\title{
Designed cellulose nanocrystal surface properties for improving barrier properties in polylactide nanocomposites
}

\author{
Etzael Espino-Pérez ${ }^{\mathrm{a}, \mathrm{b}}$, Julien Bras ${ }^{\mathrm{a}, \mathrm{c}}$, Giana Almeida ${ }^{\mathrm{b}}$, Cédric Plessis ${ }^{\mathrm{b}}$, Naceur Belgacem ${ }^{\mathrm{a}, \mathrm{c}}$, \\ Patrick Perré ${ }^{\mathrm{d}}$, Sandra Domenek ${ }^{\mathrm{b}, *}$ \\ ${ }^{\text {a } U n i v e r s i t y ~ G r e n o b l e ~ A l p e s, ~ L G P 2, ~ F-38000 ~ G r e n o b l e, ~ F r a n c e ~}$ \\ ${ }^{\mathrm{b}}$ UMR Ingénierie Procédés Aliments, AgroParisTech, INRA, Université Paris Saclay, F-91300 Massy, France \\ c CNRS, LGP2, F-38000 Grenoble, France \\ d LGPM, CentraleSupélec, Université Paris-Saclay, 8-10 rue Joliot-Curie, 91190 Gif-sur-Yvette
}

\section{A R T I C L E I N F O}

\section{Keywords:}

Poly(lactic acid)

Cellulose nanowhiskers

Non-Fickian diffusion

Polymer swelling

Partitioning

Packaging

\begin{abstract}
A B S T R A C T
Nanocomposites are an opportunity to increase the performance of polymer membranes by fine-tuning their morphology. In particular, the understanding of the contribution of the polymer matrix/nanofiller interface to the overall transport properties is key to design membranes with tailored selective and adsorptive properties. In that aim, cellulose nanocrystals (CNC)/polylactide (PLA) nanocomposites were fabricated with chemically designed interfaces, which were ensuring the compatibility between the constituents and impacting the mass transport mechanism. A detailed analysis of the mass transport behaviour of different permeants in CNC/PLA nanocomposites was carried out as a function of their chemical affinity to grafted $\mathrm{CNC}$ surfaces. Penetrants $\left(\mathrm{O}_{2}\right.$ and cyclohexane), which were found to slightly interact with the constituents of the nanocomposites, provided information on the small tortuosity effect of CNC on diffusive mass transport. The mass transport of water (highly interacting with CNC) and anisole (interacting only with designed CNC surfaces) exhibited non-Fickian, Case II behaviour. The water vapour caused significant swelling of the CNC, which created a preferential pathway for mass transport. CNC surface grafting could attenuate this phenomenon and decrease the water transport rate. Anisole, an aromatic organic vapour, became reversibly trapped at the specifically designed CNC/ PLA interface, but without any swelling or creation of an accelerated pathway. This caused the decrease of the overall mass transport rate. The latter finding could open a way to the creation of materials with specifically designed barrier properties by designing nanocomposites interfaces with specific interactions towards permeants.
\end{abstract}

\section{Introduction}

Polymer nanocomposites are attracting significant academic and industrial research interest because they offer the opportunity to tailor the membrane performances, such as permeability or barrier, and selectivity. Polylactide (PLA) is one of the most popular biodegradable and bio-based polymers and its nanocomposites have been intensively investigated, as attested by literature reviews (Rhim, Park, \& Ha, 2013; Stark, 2016). The fabrication of bionanocomposites, i.e. bio-based polymers including bio-based nanofillers has attracted particular interest in this domain, because it allows the making of claims such as $100 \%$ bio-based and biodegradable in applications. With this respect cellulose nanostructures are interesting because biobased and biodegradable themselves while being also performing in several applicative environments (Fortunati et al., 2017; Mariano, El Kissi, \& Dufresne,
2016; Minelli et al., 2010; Sung, Chang \& Han, 2017; Yu, Yang, Lu, Chen, \& Yao, 2016) and in several polymers (Arrieta et al., 2014; Fortunati et al., 2016, 2017). PLA nanocomposites were already largely studied. The inclusion of nanoclays has helped to increase the barrier to oxygen by a factor two to four (Bordes, Pollet, \& Averous, 2009; Duan, Thomas, \& Huang, 2013). The inclusion of CNC (Espino-Perez et al., 2013; Fortunati, Armentano et al., 2012; Sanchez-Garcia \& Lagaron, 2010) or metal organic frameworks (Huang et al., 2014) yielded comparable or even lower results. Although it exists an important amount of literature data, detailed studies of the mass transport properties of PLA and its nanocomposites beyond the description of experimental facts are rare. The authors (Davis, Minelli, Baschetti, \& Elabd, 2013; Davis, Minelli, Baschetti, Sarti, \& Elabd, 2012) undertook an excellent analysis of water sorption and mass transport in PLA. They addressed nonFickian (Davis et al., 2013) diffusion as modelled with the Berens and

\footnotetext{
* Corresponding author at: UMR Ingénierie Procédés Aliments, AgroParisTech, INRA 1, Rue des Olympiades, F-91744 Massy Cedex, France.

E-mail address: sandra.domenek@agroparistech.fr (S. Domenek).
} 
Hopfenberg equation (Berens \& Hopfenberg, 1978) and non-equilibrium sorption (Davis et al., 2012) as predicted with the non-equilibrium lattice fluid (NELF) model. To better design the morphology of nanocomposites with the aim of tailoring permeability as a function of application, a detailed analysis and understanding of the transport properties of permeants is required. One of the outstanding properties of nanofillers is the very high interface area with the polymer matrix. This interface area, besides being key to the compatibility between partners, contributes to the mass transport properties beyond the tortuosity effect brought about by physical obstacles in the diffusive pathway (Gotsis, 2009, 2012;). To date, the effects of the interface have barely been investigated. In a number of cases models such as the tortuous-path model introduced by Nielson fail to describe the experimental results (Tan \& Thomas, 2016). In the case of low compatible interaction between partners, the interface can be depleted, which causes a local density decrease, while in the case of favourable interaction, particles can be bridged and the local density augmented (Ganesan, Ellison, \& Pryamitsyn, 2010; Hall \& Schweizer, 2010). A numerical simulation of the mass transport further predicts that the distribution of particles, which reversibly traps permeants, can potentially decrease the diffusion coefficient (Karayiannis, Mavrantzas, \& Theodorou, 2001; Vitrac \& Hayert, 2007). Several authors have demonstrated the positive impact of interfaces on the barrier properties to gas (Bandyopadhyay et al., 2016; Clemenson, Espuche, David, \& Leonard, 2010; Hanson, Pryamitsyn, \& Ganesan, 2012) or organic molecules (Fang, Vitrac, Domenek, \& Ducruet, 2012).

PLA/CNC nanocomposites are an advantageous system to study mass transport, because there are already a number of experimental data, CNCs have a reactive surface holding the opportunity to chemically design nanofiller/polymer matrix interfaces, and, on top of it, those nanocomposites have applicative relevance in the field of packaging. One difficulty with the fabrication of PLA/CNC nanocomposites is that the two materials have low compatibility, which leads to aggregation of the CNC and thereby hinders the efficient distribution of the nanofillers in the polymer matrix. In this work, we propose the use of CNC surface grafting to combine the enhancement of the compatibility of the surface graft with the possibility of tailoring the CNC surface for specific adsorption (or not) of permeant molecules and thereby probe the nanofiller surface effects on transport properties. To that end, the CNC was surface grafted with aromatic molecules through the application of the SolReact reaction (Espino-Perez, Domenek, Belgacem, Sillard, \& Bras, 2014). Aromatic functions are well soluble in PLA, a result, which was obtained by the calculation of the solubility parameters of aromatic molecules in PLA and confirmed by the measurement of the solubility coefficient of benzaldehyde in PLA (Salazar, Domenek, Courgneau, \& Ducruet, 2012; Salazar, Domenek, \& Ducruet, 2014). Therefore we expected the compatibility to be enhanced. Furthermore, in a previous paper, we reported on the possibility of creating CNC surfaces for the preferential sorption of volatile organic compounds using this surface grafting technique (Espino-Perez et al., 2016). Recent studies of nanocomposites have shown, moreover, that the changes in the barrier properties of semicrystalline polymers were chiefly caused by the crystallinity of the polymer (Charlon et al., 2015). CNCs have a nucleating effect on a polymer, which causes crystallisation during polymer processing (Espino-Perez et al., 2013) thus making it complex to separate the effect of the crystallinity from that of the nanofiller on the barrier properties. Therefore, for this work, we chose a PLA with a high D-lactic acid content, which cannot crystallise under commonly used processing conditions. The compatibility of surface-grafted CNC with PLA was investigated through microscopic studies and thermo-mechanical analysis. The effect of the CNC and grafted CNC was measured by performing vapour permeability experiments $\left(\mathrm{O}_{2}\right.$ and $\left.\mathrm{H}_{2} \mathrm{O}\right)$. An assessment of the impact of the surface chemistry of CNC on the transport properties was performed by analysing the sorption kinetics of different probe molecules into PLA nanocomposites. We used water vapour, because of its high real-world importance and its affinity to the free CNC surface, as well as anisole, a non-toxic aromatic compound used in the food industry. We also used cyclohexane, which has similar molecular dimensions to those of anisole, but without the aromatic function, for comparison. The sorption of both molecules on grafted CNC surfaces has already been reported in a previous work (Espino-Perez et al., 2016).

\section{Experimental section}

\subsection{Materials}

Microcrystalline cellulose (MCC) AVICEL ${ }^{\circledR}$ PH-101 was acquired from Sigma-Aldrich (France) and was used as the raw reference material for the production of cellulose nanocrystals (CNC). Phenylacetic acid (PhAA) and hydrocinnamic acid (BzAA) were obtained from Aldrich (France). Anisole and cyclohexane were purchased from SigmaAldrich (France). Sulphuric acid ( $>95 \mathrm{wt} \%$ ), chloroform, acetone, and ethanol were purchased from Chimie-Plus. PLA 4060D was purchased from Natureworks. The latter contains $12 \mathrm{~mol} \%$ of D-lactic acid, which prevents crystallisation during film processing. All of the PLA samples were therefore amorphous.

\subsection{Production of cellulose nanocrystals}

CNCs were prepared by the acid hydrolysis of bleached microcrystalline cellulose using the protocol of Ref. (Espino-Perez et al., 2014). MCC at a concentration of $7.1 \mathrm{wt} \%$ was dispersed in water. Sulphuric acid was slowly added to reach a concentration of $64 \mathrm{wt} \%$. The acid hydrolysis of MCC was carried out at $44^{\circ} \mathrm{C}$ for $130 \mathrm{~min}$ with mechanical stirring. The excess sulphuric acid was removed by the application of a water exchange/centrifugation cycle and the suspension was dialysed in deionised water for one week. The system was homogenised using an Ultra-Turrax T25 homogeniser (France) and subjected to an ultrasound source (Branson 250 sonifier) during $5 \mathrm{~min}$ at $40 \%$ of amplitude. Finally, the CNC suspension was neutralised and a drop of chloroform was added to prevent microbial development. The CNC nanocrystals had a crystallinity degree of $84 \%$ (Espino-Perez et al., 2014).

\subsection{Surface esterification of CNC}

The grafting of CNC was carried out by applying the SolReact method (Espino-Perez et al., 2014) and the structure of the grafted CNC is presented in the associated data-in-brief (dib) article (Espino Perez et al., 2017), dib-figure 1. In brief, the esterification of the hydroxyl groups at the surfaces with BzAA and PhAA was done by an in situ solvent exchange at $130^{\circ} \mathrm{C}$ for $20 \mathrm{~h}$. This method consists in mixing the carboxylic acid in excess with the CNC suspension. Then the reaction mixture is heated at a temperature higher than the boiling point of water and lower that the boiling point of the carboxylic acid. This allows the continuous evaporation of the water, initially present and formed by the esterification reaction and to change gradually the solvent of the CNC suspension from water to the carboxylic acid without drying the CNC. The degree of substitution was 0.5 (BzAA) and 0.3 (PhAA), which corresponds to the number of grafted molecules for 10 anhydroglucose units. The degree of surface substitution measured by XPS was 1.25 and 1.06 for BzAA and PhAA, respectively. The detailed methodology can be found in ref. (Espino-Perez et al., 2014). The crystallinity degrees were 77 and $76 \%$ for CNC-g-PhAA and CNC-gBzAA, respectively.

\subsection{Production of nanocomposite films}

Neat PLA and nanocomposite films were prepared using the casting method. The unmodified and grafted CNC were solvent-exchanged to chloroform by the application of centrifugation/redispersion cycles. 
The final suspension concentration was $0.5 \mathrm{wt} \% \mathrm{CNC}$. The dispersion was achieved by subjecting the suspensions to ultrasound treatment three times for $5 \mathrm{~min}$ at $40 \%$ amplitude (Branson 250 Sonifier). Then, an adequate quantity of PLA pellets was added to the CNC dispersion to achieve a final CNC concentration of 2 or $6 \mathrm{wt} \%$. The suspension was stirred at room temperature for $3 \mathrm{~h}$ until the PLA was completely dissolved. Subsequently, the suspension was again subjected to ultrasound treatment for three periods of $5 \mathrm{~min}$ at $40 \%$ amplitude. Then, the suspension was cast into glass Petri dishes. The solvent was evaporated at room temperature at least for $24 \mathrm{~h}$. To remove any residual solvent and homogenise the sample morphology, the films were sandwiched between two Teflon sheets and melted in a heating press (Telemecanique, France) between two steel plates without pressure for $3 \mathrm{~min}$ at $180^{\circ} \mathrm{C}$. The films were then pressed for $3 \mathrm{~s}$ at $150 \mathrm{bar}$ and quenched to room temperature under air. The films were $60-80 \mu \mathrm{m}$ thick, with a standard deviation of $20 \%$. They were stored over $\mathrm{P}_{2} \mathrm{O}_{5}$ at room temperature. The thermal stability of the nanocomposites at the hot-moulding temperature was checked with the help of thermo-gravimetric analysis and the corresponding data can be found in the data-in-brief file (dib-table 1) (Espino Perez et al., 2017).

\subsection{Morphological and thermo-mechanical characterisation of nanocomposites}

\subsubsection{Scanning electron microscopy (SEM)}

Scanning electron microscopy was used to observe the cryofractured surface (fracture under liquid nitrogen) of the nanocomposites, using an ABT-55 microscope with an applied voltage of $10 \mathrm{kV}$. An average of 5 images were captured of one sample.

\subsubsection{Transmission electron microscopy (TEM)}

TEM was performed using the analysis platform of the University of Brittany (Brest, France) on a JEOL 1400. The sample cuts were realised by cryo-ultramicrotomy (Leica).

\subsubsection{Differential scanning calorimetry}

The transition temperature $\left(T_{g}\right)$ of PLA was evaluated on a DSC 1 (Mettler Toledo, France), calibrated with Id and Zn standards. The film samples (4-6 mg) were put into aluminium pans (Standard pan, $40 \mu \mathrm{L}$ ) and analysed by a heat-cool-heat scan at a scanning speed of $10{ }^{\circ} \mathrm{C} \mathrm{min}{ }^{-1}$ from $-10{ }^{\circ} \mathrm{C}$ to $190^{\circ} \mathrm{C}$ under $\mathrm{N}_{2}$ flow $\left(30 \mathrm{mLmin}^{-1}\right)$. All experiments were carried out in duplicate.

\subsubsection{Dynamic mechanical analysis (DMA)}

The measurement of the thermo-mechanical properties was carried out using a DMA RSA3 (TA Instruments, USA) device operating in tensile mode. The measurements were performed at a constant frequency of $1 \mathrm{~Hz}$ and a strain amplitude of $0.05 \%$ over a temperature range of $30^{\circ} \mathrm{C}$ to $150{ }^{\circ} \mathrm{C}$ at a scanning speed of $2{ }^{\circ} \mathrm{C} \mathrm{min}^{-1}$. The distance between the jaws was $10 \mathrm{~mm}$ and the sample width was $5.5 \mathrm{~mm}$. The film thickness was determined before each measurement. Data acquisition was carried out using the TA Orchestrator 7.0 software. Two samples were used to characterise each film.

\subsection{Mass transfer trough nanocomposites}

\subsubsection{Water and oxygen permeability}

The oxygen transmission rate (OTR) was measured using a Systech Instruments oxygen permeation analyser 8001 (France). The analysis was carried out at $23{ }^{\circ} \mathrm{C}$ and $0 \% \mathrm{RH}$. The sample area was $50 \mathrm{~cm}^{2}$ and the pressure gradient of the oxygen was $1 \mathrm{~atm}$. The OTR was normalised with respect to the oxygen pressure, area, and thickness of the films to yield the oxygen permeability.

The water vapour transmission rate (WVTR) of the films was measured according to the standard procedure, NF $\mathrm{H} 00-030$, at $25^{\circ} \mathrm{C}$ and $90 \% \mathrm{RH}$. The procedure consisted of the measurement of the weight uptake (using a Kern 770 balance, Kern, Germany (precision of $0.01 \mathrm{mg}$ )) of dried $\mathrm{CaCl}_{2}$. The $\mathrm{CaCl}_{2}$ was placed in a metal cap, sealed with the sample films and tightened by the application of beeswax. The specific exchange surface was $50.24 \mathrm{~cm}^{2}$. To control the environmental conditions, the cups were placed in a climatic chamber (VCN100, Vötsch Industrietechnik, Germany). The WVTR $\left(\mathrm{kg} \mathrm{m} \mathrm{m}^{-2} \mathrm{~s}^{-1}\right)$ was obtained from the slope of the weight uptake, corrected by the sample thickness and normalised by the pressure gradient as described in Espino-Perez et al. (2013). The measurements of the OTR and WVTR were performed in triplicate. The general error in the measurements, including the variability of the sample thickness due to the casting process, was estimated to be $10 \%$.

\subsubsection{Water vapour sorption}

The water vapour sorption was performed by using dynamic vapour sorption with a DVS intrinsic apparatus (Surface Measurement Systems, London, UK). The nanocomposite film samples were rejuvenated before measurement at $60^{\circ} \mathrm{C}$ for $30 \mathrm{~min}$. This temperature is slightly higher than the PLA glass transition temperature. This treatment reduces the physical aging of the PLA samples without inducing morphological changes. The DVS is an ultra-sensitive micro-balance allowing the measurement of sample mass variations as low as $0.1 \mu \mathrm{g}$. The accuracy of the system is $\pm 0.5 \%$ for the relative humidity ( $\mathrm{RH}$ ) of $0-98 \%$ and $\pm 0.3{ }^{\circ} \mathrm{C}$ for a measuring temperature of $25^{\circ} \mathrm{C}$. A support pan was specially designed to allow the entire film surface to be available for the vapour exchange. Approximately $20 \mathrm{mg}$ of sample was placed in the sample pan. The sample was then subjected to a constant flow of nitrogen gas, mixed with a preset amount of water vapour. The nitrogen passes through the chamber to maintain the desired $\mathrm{RH}$ level. The samples were first equilibrated at $0 \% \mathrm{RH}$ over $360 \mathrm{~min}$. The amount of dry matter was determined at the end of this plateau. Then, the RH was increased to $30 \%$ and maintained at this level for $1440 \mathrm{~min}$. Finally, the $\mathrm{RH}$ was increased to $90 \%$ and maintained at this level for $2880 \mathrm{~min}$. Preliminary tests confirmed that the duration of each RH plateau was sufficient to attain the equilibrium condition (the rate of change of mass per unit time $(\mathrm{dm} / \mathrm{dt})$ was less than $0.0005 \% / \mathrm{min})$. The data were saved every $20 \mathrm{~s}$. The measurements were carried out in duplicate.

\subsubsection{Anisole and cyclohexane sorption}

The gravimetric method was also used for the measurement of the anisole and cyclohexane sorption kinetics. The sorption curves were recorded at $40{ }^{\circ} \mathrm{C}$ and $0 \% \mathrm{RH}$, using an electronic microbalance operating at a fixed partial pressure (Intelligent Gravimetric Analyser 002, Hiden Isochema Ltd, Warrington, UK, (precision $0.2 \mu \mathrm{g}$ )). Film samples of a known geometry (30-40 mg, thickness $20-50 \mu \mathrm{m}$ ) were suspended from the microbalance by a stainless steel spiral, which was contained in a thermo-regulated cell. The microbalance itself was maintained at $50{ }^{\circ} \mathrm{C}$ to ensure stability during the weight measurement and prevent solvent condensation. To ensure a very low water content, the samples were stored in a desiccator over $\mathrm{P}_{2} \mathrm{O}_{5}$ for at least one month before the measurements. The film samples were rejuvenated before the measurement as mentioned above in the paragraph describing water vapour sorption. After the samples had been loaded into the microbalance, they were purged for $24 \mathrm{~h}$ at $10^{-5} \mathrm{mbar}\left(10^{-3} \mathrm{~Pa}\right)$ to remove all volatile compounds, which were sorbed in the film and present in the chamber. The anisole or cyclohexane partial pressure, which corresponded to an activity of 0.2 (229.8 and 4955.3 Pa, respectively, dib-table 3, (Espino Perez et al., 2017), was set in the measuring chamber, which was connected to a tank with a vapour phase saturated in anisole or cyclohexane. The partial pressure was regulated using a pressure transducer (Baratron ", MKS Instruments, Wilmington, MA, USA). The mass uptake of the samples was recorded automatically over 5 days. The results of the preliminary experiments showed that there is some inevitable leakage past the copper seals which, over time, leads to the dilution of the organic vapours by incoming air. Therefore, a pressure perturbation was introduced at regular time intervals to ensure a 
constant partial pressure while the measurement was being performed. This pressure perturbation forces the electronics of the microbalance to re-regulate the partial pressure by pumping part of the atmosphere in the chamber and re-regulating by connecting the organic vapour reservoir. It has a time constant, which is very different from the characteristic time of diffusion. Therefore, it was easily cancelled out in the curve analysis. In the following, the pressure perturbation is visible in the experimental data and corresponds to the spikes in the mass uptake curves. The sample measurements were performed in duplicate.

\subsection{Diffusion coefficient determination by inverse method}

The general principle of identification of diffusion coefficient by the inverse method used in the present word is presented in Perre, Pierre, Casalinho, and Ayouz (2015). The known sample characteristics (thickness, density, sorption isotherm) and the estimated values of unknown parameters (diffusion coefficient, initial permeant content, external heat transfer coefficient) were supplied to the comprehensive model (TransPore) (Perre \& Turner, 1999). Using the recorded conditions of the IGA and DVS apparatus as boundary conditions, the computational code was able to predict the mass uptake of the samples. Concerning the physical model, a 2-variable model was chosen (Perre et al., 2015) which is likely to represent diffusion in one-phase product such as gels and dense films. The simplified transport equations were as follows:

Permeant conservation

$\rho_{s} \frac{\partial X}{\partial t}=\nabla \cdot\left(\boldsymbol{D}_{b, \rho_{v}} \nabla \rho_{v}\right)$

Energy conservation

$\frac{\partial}{\partial t}\left(\overline{\rho_{b}} \overline{h_{b}}+\varepsilon_{s} \rho_{s} h_{s}\right)=\nabla \cdot\left(\lambda_{e f f} \nabla T+h_{b} \boldsymbol{D}_{b, \rho_{v}} \nabla \rho_{v}\right)$

Boundary conditions

$\left.J_{v}\right|_{x=0^{+} \cdot \boldsymbol{n}}=k c M_{v} \ln \left(\frac{1-x_{v, \infty}}{1-x_{v, \text { surf }}}\right)$

$\left.J_{q}\right|_{x=0^{+}} \cdot \boldsymbol{n}=h\left(T_{\text {surf }}-T_{\infty}\right)$

where $\boldsymbol{J}_{\boldsymbol{v}}$ and $\boldsymbol{J}_{q}$ represent the fluxes of permeant vapour and the heat at the boundary, respectively, while $\mathrm{x}$ denotes the distance from the boundary along the external unit normal. In the present work, the enthalpy of bound permeant is assumed to be equal to that of liquid permeant. Note also that the external flux of permeant occurs as permeant vapour whose enthalpy is much larger than the enthalpy of liquid. This induces a strong heat and mass coupling at the interface, which is accounted for by the computer code TransPore. This coupling, which always tends to slow down the external transfer, must be accounted for the identification procedure to be accurate (Perre et al., 2015).

The difference between predicted and experimental values was quantified by an objective function $\mathrm{S}$, which was defined as the sum of the squared residues:

$S=\sum_{i=1}^{N T} w_{i}\left[M_{\exp }\left(t_{i}\right)-M_{\text {pred }}\left(t_{i}\right)\right]^{2}$

Where $M_{\text {exp }}$ is the experimental value, $M_{\text {pred }}$ is the predicted value of the TransPore Model, $w_{i}$ the weighting coefficient, $t$ the time, and $N T$ is the number of time intervals. In this work, we used a uniform weighting factor throughout the test, which means that $w_{i}$ was proportional to the time interval between two successive data acquisitions. An optimization algorithm (Simplex) was used to minimize this function by modifying the unknown parameters (Press, Teukolski, Vetterling, \& Flannery, 1992). The diffusivity was given as the value reached after convergence. The pseudo-Fickian plateau value was determined as the average of the fitted plateau of the pseudo-Fickian curve. The dib-figure 2 (Espino Perez et al., 2017) shows an example of modelling of the PLA permeant sorption kinetics.

\section{Results and discussion}

\subsection{Morphological analysis of nanocomposites}

The dispersion of nanofillers inside the polymer matrix, which is one of the key parameters affecting the understanding of the performance of the material, was checked with the naked eye and analysed by electron microscopy. The low compatibility of the neat CNC with PLA gave rise to aggregates, which were visible with the naked eye. The dibfigure 3 shows the corresponding photographs (Espino Perez et al., 2017). The aggregates were not observed when using grafted CNC. The Fig. 1 shows the SEM micrographs of the cryofractured samples. The pure PLA had, as expected, a flat and homogenous fracture surface. The inclusion of $\mathrm{CNC}$ resulted in the occurrence of some pores, which were remnants of the $\mathrm{CNC}$ aggregates (Fig. 1, picture $\mathrm{CNC}$ ). These were more numerous for the $6 \mathrm{wt} \%$ CNC. PLA containing CNC-g-BzAA and CNC-gPhAA exhibited flat and homogenous fracture surfaces, comparable to that of pure PLA. Careful inspection showed that the PLA/CNC-g-PhAA

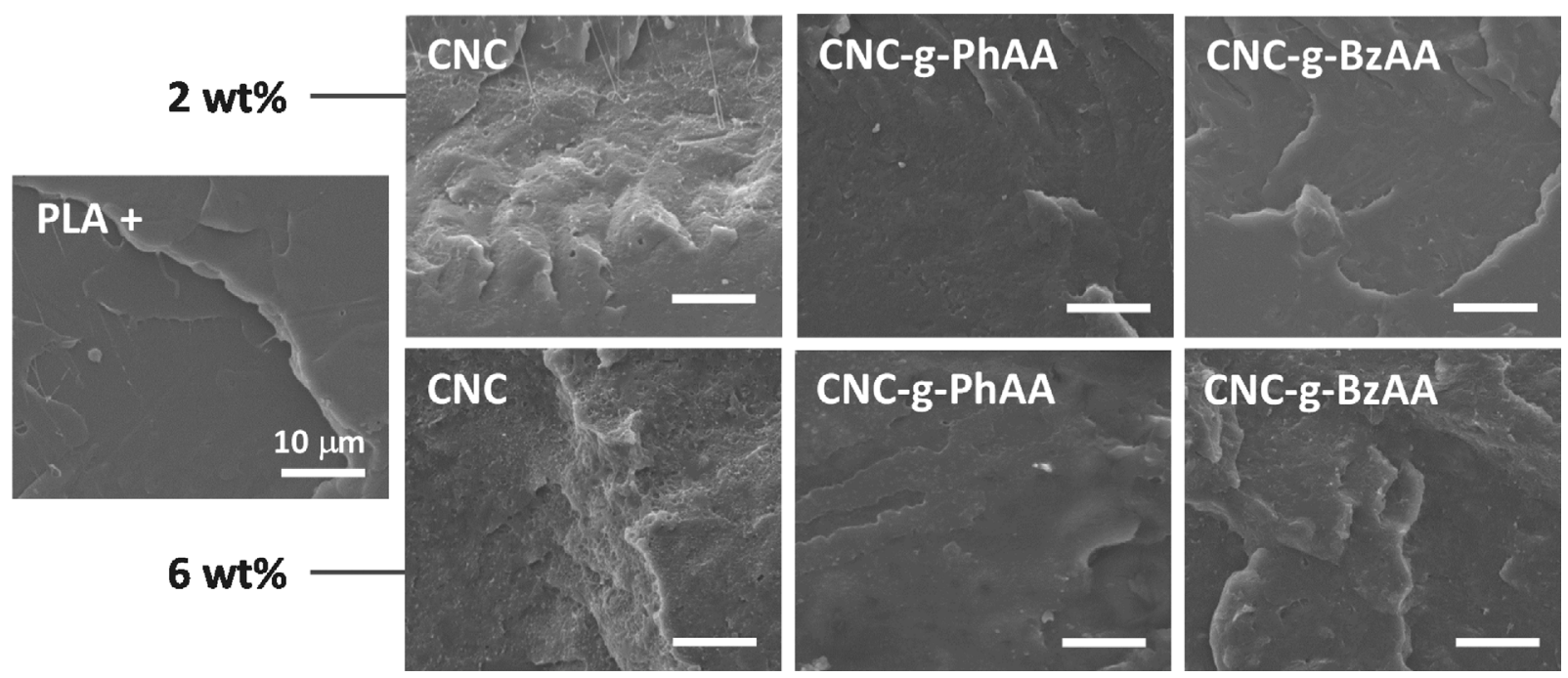

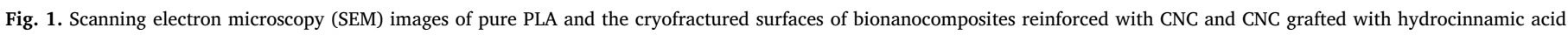
(CNC-g-BzAA) and phenyl acetic acid (CNC-g-PhAA) at 2 and $6 \mathrm{wt} \%$. 


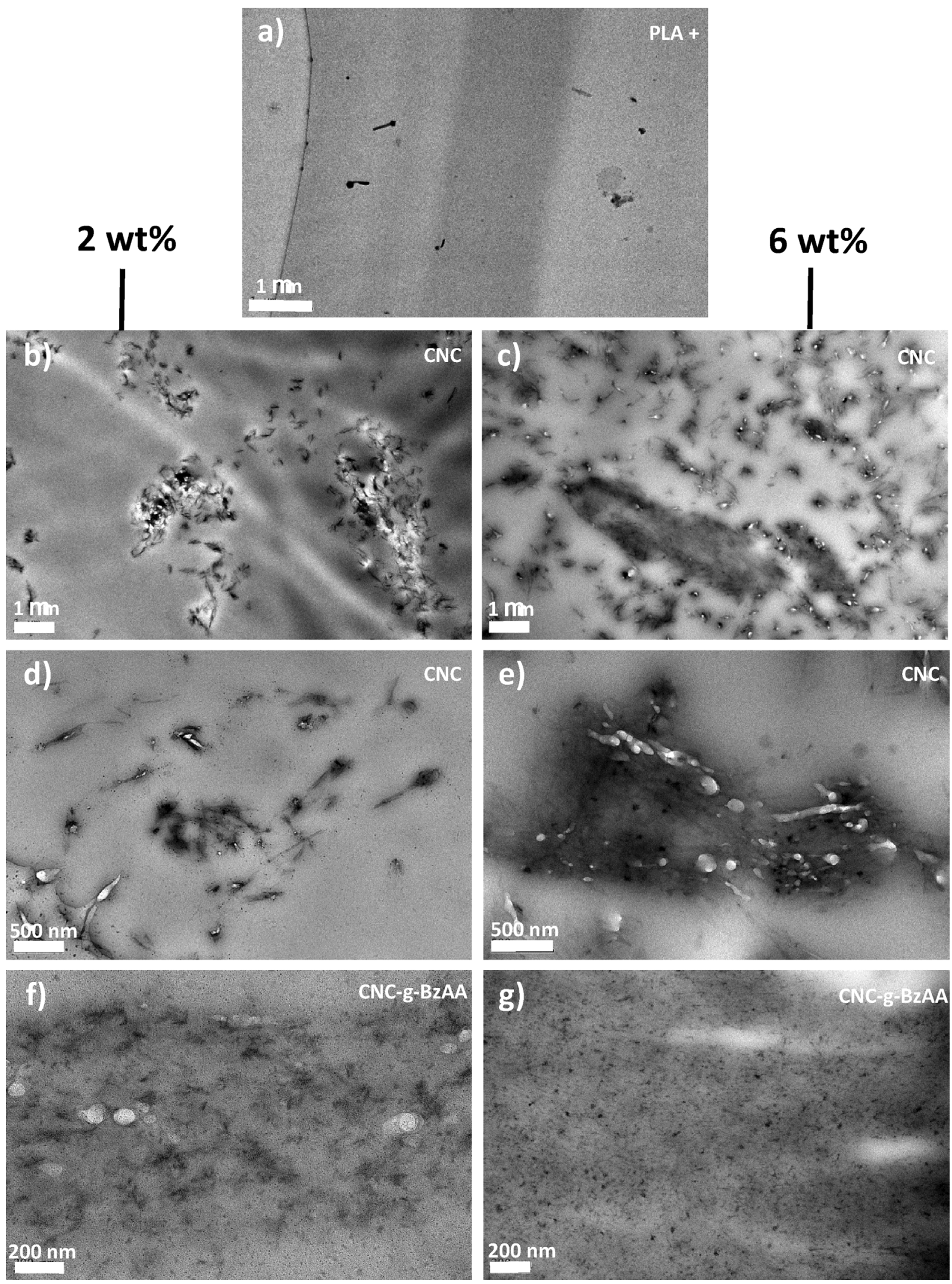

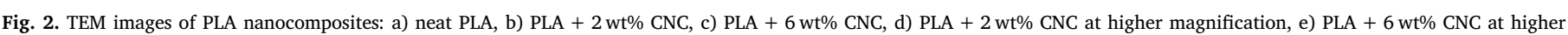
magnification, f) PLA $+2 w t \%$ CNC-g-BzAA, g) PLA $+6 w t \%$ CNC-g-BzAA.

nanocomposites seemed slightly more porous (compare CNC-g-PhAA with CNC-g-BzAA in Fig. 1).

The morphological analysis of the lower length scale by TEM was done only for CNC-g-BzAA, which yielded the most homogenous samples. Fig. 2 shows the obtained TEM images. It can be clearly observed that the unmodified CNC forms aggregates in the PLA matrix (Fig. 2b-e) 
and that the aggregates are larger at higher CNC concentrations (Fig. 2d vs. e). Rusli, Shanmuganathan, Rowan, Weder, and Eichhorn (2010) showed that a cluster structure could be obtained by heat-treatment of the cast $\mathrm{CNC}$ /polymer samples, which appears to be the case here. The aggregates resemble clusters of CNC and these clusters seem to percolate throughout the sample at a concentration of $6 \mathrm{wt} \%$ (Fig. 2b vs. c). The distribution of the grafted CNC in the PLA matrix was more homogeneous (Fig. 2d vs. f and e vs. g). It can also be observed that there was less contrast between the CNC and PLA in that case. As a conclusion, the surface grafting of CNC by PhAA and BzAA had a positive effect on the distribution homogeneity of CNC in the PLA nanocomposites and, between both molecules, BzAA seemed to be more efficient.

\subsection{Thermo-mechanical properties of nanocomposites}

Due to the large surface area of the nanoparticles, interfacial effects are expected to be relevant to the relaxation processes of the surrounding polymer chains. In terms of the function of the interfacial compatibility between both partners, polymer chains can be either attracted to or repulsed from the interface, and a shift of $\mathrm{Tg}$ was reported by some authors (Krishnamoorti \& Vaia, 2007). The surface area of the present nanofillers was measured by Espino-Perez et al., 2016 with different probe molecules. The BET surface area using $\mathrm{N}_{2}$ amounted to 22, 52, and $126 \mathrm{~m}^{2} \cdot \mathrm{g}^{-1}$ for CNC, CNC-g-PhAA, and CNC-g-BzAA respectively.

Table 1 shows the Tg of the PLA and nanocomposites as measured at the second heating scan after erasing the thermal history of the samples. We like to recall that the PLA was amorphous in all studied samples due to its high D-lactic acid content. Therefore, only the glass transition region was analysed. The $\mathrm{Tg}$ of the nanocomposites was not significantly different from that of the pure PLA. Also, an inspection of the thermograms showed the almost perfect superposition of the DSC signals of the different samples, without any enlargement of the glass transition region. The absence of the effect of distribution of CNC in PLA on the glass transition was also reported by others for PLA/CNC (Lee, Park, \& Kim, 2013), PLA/CNC grafted with octadecyl isocyanate (Espino-Perez et al., 2013), and PLA/cellulose nanofibre composites (Ahmad \& Luyt, 2012).

To examine the effect of surface grafting on the compatibility between the PLA and grafted CNC, the dynamic mechanical properties below and above Tg were assessed. Fig. 3 shows the DMA curves of amorphous PLA and films reinforced with CNC, CNC-g-PhAA, and CNCg-BzAA. The curves showed a decrease in the elastic storage modulus caused by the glass transition of amorphous PLA (Courgneau, Domenek, Guinault, Averous, \& Ducruet, 2011; Espino-Perez et al., 2013). Furthermore, the crystallisation of PLA in the rubbery plateau does not occur, which confirms the amorphous characteristics of the chosen PLA type. To ease the identification of any differences in the rubbery plateau, we applied the normalisation method to the curves in the glassy plateau (at $30^{\circ} \mathrm{C}$ ), as proposed by Azizi, My, Alloin, and Dufresne (2005). The rubbery storage modulus (E') of PLA/CNC $2 \mathrm{wt} \%$ was equal to that of the PLA control sample. PLA/CNC-g-BzAA $2 \mathrm{wt} \%$ and PLA/ CNC-g-PhAA $2 \mathrm{wt} \%$ both had a clearly higher rubbery plateau modulus. No differences in the behaviour of the two types of surface grafts were

Table 1

Glass transition temperature of bionanocomposites measured at the second heating scan.

\begin{tabular}{lll}
\hline Sample & \multicolumn{2}{l}{$\mathrm{T}_{\mathrm{g}}\left({ }^{\circ} \mathrm{C}\right)$} \\
\cline { 2 - 3 } & $2 \mathrm{wt} \%$ & $6 \mathrm{wt} \%$ \\
\hline PLA & $56.4 \pm 0.9$ & \\
PLA/CNC & $56.5 \pm 1.2$ & $56.1 \pm 1.0$ \\
PLA/CNC-g-PhAA & $56.0 \pm 0.7$ & $57.0 \pm 0.9$ \\
PLA/CNC-g-BzAA & $56.3 \pm 1.0$ & $56.5 \pm 1.3$ \\
\hline
\end{tabular}

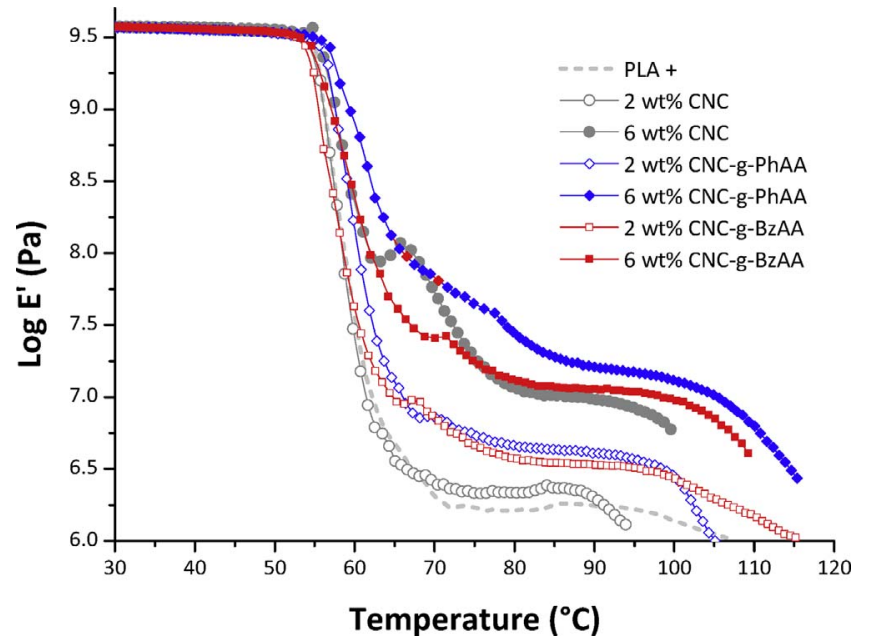

Fig. 3. Logarithm of the normalised elongation storage modulus (E') as a function of temperature for PLA and PLACNC, PLA/CNC-g-BzAA, and PLA/CNC-g-PhAA nanocomposites at the concentrations 2 and $6 \mathrm{wt} \%$.

observed. At a CNC concentration of $6 \mathrm{wt} \%$, all of the nanocomposites exhibited an improved rubbery plateau modulus. The glass transition region broadened slightly which can be interpreted as due to higher structural heterogeneity in the material. The best performance was achieved with CNC-g-PhAA (28.2 MPa at $80^{\circ} \mathrm{C}$ ). Rusli et al. (2010) reported that, at temperatures above $\mathrm{Tg}$, the percolation of CNC dominates the material properties and that the enhancement of the compatibility of the CNC by surface grafting had only a secondary role.

The percolation thresholds $\left(v_{P}\right)$ of the different CNCs were calculated by using the relation $v_{P}=0.7 / \frac{L}{d}$ (Azizi et al., 2005), where $\mathrm{L}$ is the nanofiller length and $d$ the diameter. Using the values, which are listed in the dib-table 2 (Espino Perez et al., 2017), the percolation threshold was calculated to be $8 \pm 3,6 \pm 2$, and $5 \pm 2$ for CNC, CNC-g-PhAA, and CNC-g-BzAA, respectively. Within the limits of experimental uncertainty, all of the CNC networks can be assumed to have percolated at a concentration of $6 \mathrm{wt} \%$. Accordingly, the DMA curves of the nanocomposites exhibit a rise of one order of magnitude of the rubbery plateau modules, relative to the pure PLA. The increased compatibility of PLA and CNC due to the surface grafting increased mainly the length of the temperature range of the rubbery plateau. As a general conclusion, the surface grafting of CNC led to better compatibility between the PLA and nanofillers, which increased the homogeneity of the CNC dispersion and was positive for the mechanical properties in the rubbery plateau.

\subsection{Oxygen and water vapour barrier properties of PLA/CNC nanocomposites}

The impact of the CNC surface grafting on the oxygen and water vapour barrier properties, which are both very important to the use properties of polymers, was studied. Table 2 lists the corresponding results. The oxygen permeability values of the PLA were in the range of the literature values $\left(2.15-2.61 \times 10^{-18} \mathrm{~m}^{3} \mathrm{~m} \mathrm{~s}^{-1} \mathrm{~m}^{-2} \mathrm{~Pa}^{-1}\right)$ (Colomines, Domenek, Ducruet, \& Guinault, 2008; Espino-Perez et al., 2013; Guinault, Sollogoub, Ducruet, \& Domenek, 2012; Martinez-Sanz, Lopez-Rubio, \& Lagaron, 2012). The inclusion of CNC and surfacegrafted CNC slightly, but significantly, improved the oxygen barrier properties. This result is similar to that obtained by (Martinez-Sanz et al., 2012) who used bacterial cellulose nanocrystals dispersed by electro-spinning in PLA. Electro-spinning produces similarly (or even more) efficient nanofiller distribution as the casting method. Neither the type of the chemical modification of the CNC surface, nor the increase in the CNC quantity had a specific effect on the oxygen permeability. Due the utilization of amorphous PLA in this study, a coupled 
Table 2

Water vapour and oxygen permeability of neat PLA, and nanocomposites based on PLA with unmodified and modified cellulose nanocrystals at 2 wt $\%$ and 6 wt $\%$.

\begin{tabular}{|c|c|c|c|}
\hline & CNC (wt\%) & $\mathrm{P}\left(\mathrm{O}_{2}\right) \times 10^{18}\left(\mathrm{~m}^{3} \mathrm{~m} \mathrm{~m}^{-2} \mathrm{~s}^{-1} \mathrm{~Pa}^{-1}\right)$ & $\mathrm{P}\left(\mathrm{H}_{2} \mathrm{O}\right) \times 10^{14}\left(\mathrm{~kg} \mathrm{~m} \mathrm{~m}^{-2} \mathrm{~s}^{-1} \mathrm{~Pa}^{-1}\right)$ \\
\hline PLA & & $2.7 \pm 0.3$ & $3.0 \pm 0.3$ \\
\hline PLA/CNC & 2 & $1.8 \pm 0.2$ & $2.4 \pm 0.2$ \\
\hline PLA/CNC & 6 & $1.7 \pm 0.2$ & $3.0 \pm 0.5$ \\
\hline PLA/CNC-g-PhAA & 2 & $1.9 \pm 0.2$ & $1.7 \pm 0.2$ \\
\hline PLA/CNC-g-PhAA & 6 & $1.6 \pm 0.2$ & $1.8 \pm 0.2$ \\
\hline PLA/CNC-g-BzAA & 2 & $1.6 \pm 0.2$ & $1.7 \pm 0.2$ \\
\hline PLA/CNC-g-BzAA & 6 & $1.9 \pm 0.2$ & $1.8 \pm 0.2$ \\
\hline
\end{tabular}

Table 3

Equilibrium mass uptake of anisole and cyclohexane in PLA and grafted and neat CNC powders.

\begin{tabular}{llll}
\hline & $\begin{array}{l}\mathrm{m}_{\mathrm{eq}}\left(\mathrm{H}_{2} \mathrm{O}\right)(\%) \text { at } \\
90 \% \mathrm{RH}\end{array}$ & $\mathrm{m}_{\mathrm{eq}}$ (cyclohexane) $(\%)$ & $\begin{array}{l}\mathrm{m}_{\mathrm{eq}} \text { (anisole) } \\
(\%)\end{array}$ \\
\hline PLA & $0.53^{\mathrm{b}}$ & $0.03^{\mathrm{a}}$ & $3^{\mathrm{a}}$ \\
$\mathrm{CNC}^{\mathrm{c}}$ & 160 & 0.31 & 1.1 \\
CNC-g-PhAA $^{\mathrm{c}}$ & 15 & 1.6 & 3.0 \\
CNC-g-BzAA $^{\mathrm{c}}$ & 18 & 2.9 & 5.0 \\
\hline
\end{tabular}

a The values of PLA are taken at the end of the sorption kinetics shown in dib-figure 5 (Espino Perez et al., 2017) and Fig. 5.

b Data from (Davis \& Elabd, 2013).

c Data from (Espino-Perez et al., 2016).

effect arising from increased crystallinity degree of the polymer and the presence of the nanofiller can be ruled out. The observed result was thus uniquely caused by the presence of CNC. We concluded that the tortuosity effect of CNC on the diffusion pathway was small. Indeed, the shape and aspect ratio of the fibres is not as advantageous for increasing the diffusive pathway as, for example, large thin platelets (e.g. nanoclays). Furthermore, the casting technique does not cause the fibres to be oriented in one plane, although Rusli et al. (2010) showed that the hot-pressing of cast films leads to the partial orientation of the CNC. Those small differences might be masked here by the different sample ages, because of the duration of the measurement campaign. PLA is subject to quick physical aging (Dobircau et al., 2015; Pan, Zhu, \& Inoue, 2007), which causes a reduction in the free volume of the polymer and can increase in the oxygen barrier properties (Martino, Ruseckaite, \& Jiménez, 2009).

The water vapour permeability of PLA film and its nanocomposites is also listed in Table 2. The values were comparable to the order of magnitude of the literature data (Delpouve, Stoclet, Saiter, Dargent, \& Marais, 2012; Espino-Perez et al., 2013; Luo \& Daniel, 2003; SanchezGarcia, Gimenez, \& Lagaron, 2008). The water vapour permeability was neither improved nor degraded by the incorporation of neat CNC, which was consistent with our earlier results (Espino-Perez et al., 2013) and those obtained by (Fortunati, Peltzer et al., 2012). The dispersion of the experimental data was much higher in the case of CNC nanocomposites at a concentration of $6 \mathrm{wt} \%$. This was most probably caused by the agglomeration of the CNC in the PLA matrix, as shown in SEM (Fig. 1) and TEM pictures (Fig. 2). This induced heterogeneity and additional cavities that could facilitate water vapour permeation in the samples. Martinez-Sanz et al. (2012) reported a very small improvement $(43 \%)$ of the water barrier properties at 1 and 3\% CNC. Here, a significant (although small) change in the water vapour barrier properties was obtained by using the surface-grafted CNC (Table 2). No differences between the types of surface grafting could be seen. A similar result was reported by Follain et al. (2013) on the water vapour barrier properties of poly(caprolactone) (PCL)/CNC nanocomposites including CNC and CNC grafted with octadecyl isocyanate. They showed that the inclusion of the grafted CNC allowed a slight improvement of the water vapour barrier properties, while the neat CNC were not effective.
The general conclusion of the analysis of $\mathrm{O}_{2}$ and water vapour permeability was that CNC had only a small tortuosity effect on the nanocomposites, which enhanced slightly their barrier properties. Within the experimental error, no impact of the percolation of the CNC network on the barrier properties was observed. From the viewpoint of practical applications, however, the small changes, which were observed, are not sufficient. An improvement of at least one order of magnitude in the oxygen and water vapour barrier properties of PLA would be required to match the properties of PET, a widely-used packaging polymer (Ducruet \& Domenek, 2015). Nevertheless, the observed differences between the behaviour of the oxygen and water permeability as a function of the CNC surface grafting prompted us to further pursue the analysis and to investigate the mass transport parameters in the transient permeation regime in the aim of getting an understanding of the role of the CNC/PLA interface on the mass transport.

\subsection{Transport properties of water and organic vapours in nanocomposites} as determined by sorption experiments

With the aim of analysing in greater detail the transport properties of penetrants and the role of the nanofiller interface in PLA/CNC nanocomposites, three probe molecules were selected: water, cyclohexane, and anisole. Those molecules present different chemical affinities to PLA, CNC, and grafted CNC. We indicate these differences in Table 3, which sums up the equilibrium mass uptake of these probe molecules by the PLA and CNC powders collected from the literature and the present work. The contrast between water mass uptake of the CNC and PLA is very high, with the affinity being on the side of the CNC. The contrast between cyclohexane mass uptake in CNC and PLA is less noticeable and the affinity is still higher for CNC, while there is not much difference between the anisole mass uptake of the PLA and CNC powders. As a function of the chemical nature of the CNC surface graft, the affinity of anisole can be higher for PLA or CNC.

\subsubsection{Water vapour transport in PLA/CNC nanocomposites}

The water sorption kinetics of PLA and its nanocomposites were recorded at $90 \% \mathrm{RH}$. The raw data and their modelling are presented in Fig. 4. For the analysis of the diffusion coefficient and the sorption equilibrium, the inverse method proposed by Perre, Pierre, Casalinho, \& Ayouz, 2015; Perre \& Turner, 1999 was applied. The aim of this general model is to detect non-standard, i.e. non-Fickian, diffusion behaviour. Indeed, the inspection of the sorption kinetics and the analysis with the inverse method showed that they presented non-Fickian, Case II, behaviour. The polymer film thickness and the time for observing the diffusion and polymer relaxation phenomena are inherently coupled, in that the length of the diffusive pathway (in our geometrical set-up $\mathrm{L}=$ thickness $/ 2$ ) rules the experimental time in which the Fickian equilibrium is reached. The polymer relaxation phenomenon can thus be observed using thin films (present case) or long experimental times. The case II behaviour is common in glassy polymers (Berens \& Hopfenberg, 1978) and implies that both concentration-gradient-controlled diffusion and polymer-relaxation-controlled swelling contribute to the rate of the mass transport. Moreover, cluster formation of water 

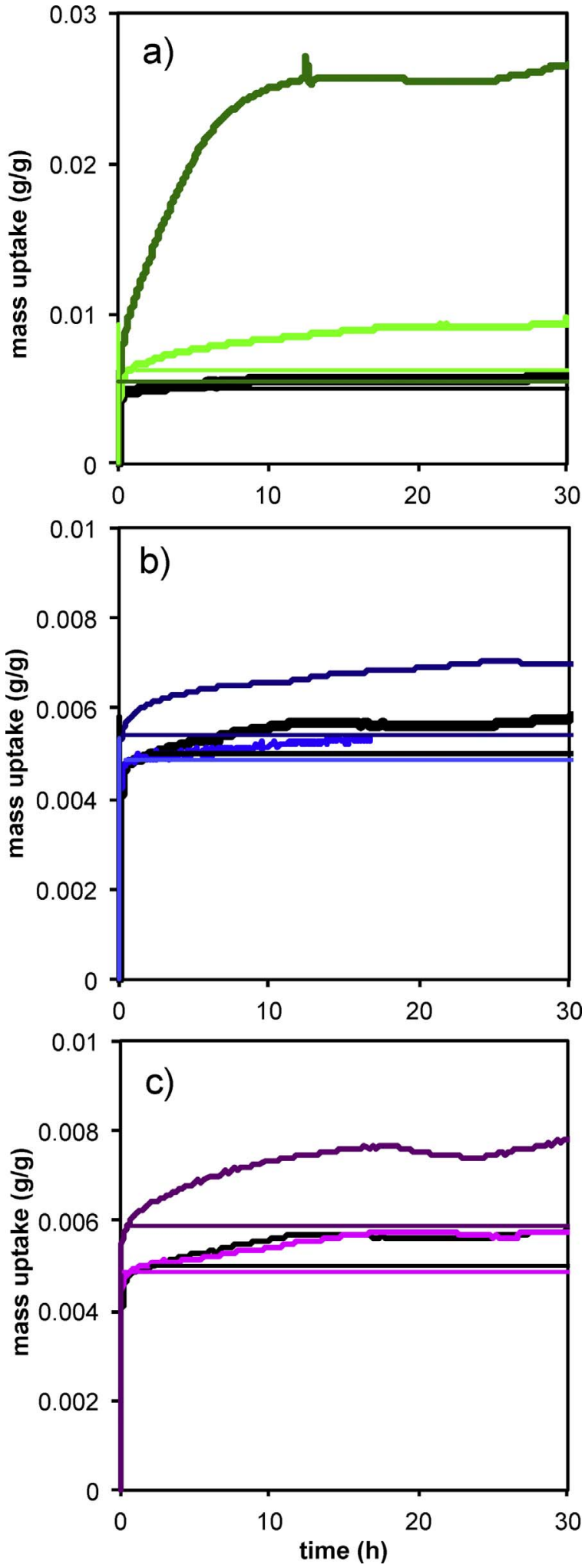

Fig. 4. Water vapour sorption kinetics into PLA nanocomposites for the step from 30 to $90 \%$ RH at $25{ }^{\circ} \mathrm{C}$ : Figure a shows PLA (black), PLA/CNC 2 wt $\%$ (light green), PLA/CNC $6 \mathrm{wt} \%$ (dark green) (scale is different from $\mathrm{b}$ and c), Figure b shows PLA as a point of comparison (black), PLA/CNC-g-BzAA 2 wt\% (light blue), PLA/CNC-g-BzAA 6 wt\% (dark blue), and Figure c shows PLA (black), PLA/CNC-g-PhAA 2 wt\% (magenta), PLA/CNC-g$\mathrm{PhAA} 6 \mathrm{wt} \%$ (violet). The value of the Fickian sorption equilibrium is indicated as a straight line of same colour than the experimental curve. (For interpretation of the references to colour in this figure legend, the reader is referred to the web version of this article.)
Table 4

Water vapour mass transport parameters measured by dynamic water sorption at $90 \% \mathrm{RH}$ and $25^{\circ} \mathrm{C}$.

\begin{tabular}{lllll}
\hline Sample & CNC $(w t \%)$ & $\mathrm{D} \times \times 10^{12}\left(\mathrm{~m}^{2} \mathrm{~s}^{-1}\right)$ & $\mathrm{m}_{\mathrm{eq}, \mathrm{F}}$ & $\mathrm{m}_{\mathrm{r}(30 \mathrm{~h})}$ \\
\hline PLA & 0 & 5.6 & 0.0050 & 0.0008 \\
PLA/CNC & 2 & 3.6 & 0.0061 & 0.0032 \\
PLA/CNC & 6 & 2.6 & 0.0055 & 0.021 \\
PLA/CNC-g-PhAA & 2 & 4.2 & 0.0048 & 0.0009 \\
PLA/CNC-g-PhAA & 6 & 2.2 & 0.0059 & 0.0019 \\
PLA/CNC-g-BzAA & 2 & 5.3 & 0.0049 & $0.0004^{\mathrm{a}}$ \\
PLA/CNC-g-BzAA & 6 & 3.0 & 0.0053 & 0.0017 \\
\hline
\end{tabular}

D diffusion coefficient, $\mathrm{m}_{\mathrm{eq}, \mathrm{F}}$ equilibrium mass uptake at the pseudo-Fickian plateau, $\mathrm{m}_{\mathrm{r}(30 \mathrm{~h})}$ difference of the measured mass uptake and the pseudo-Fickian plateau at $30 \mathrm{~h}$ attributed to Case II diffusion.

${ }^{\mathrm{a}}$ Measurement at $20 \mathrm{~h}$ due to problem in DVS temperature regulation.

inside PLA at activities higher than 0.65 has been described (Davis et al., 2012). The presence of clusters is favoured by a sorption enthalpy of water in PLA $(-40 \mathrm{~kJ} / \mathrm{mol})$ close to the heat of vaporisation of water $(-44 \mathrm{~kJ} / \mathrm{mol}$ ) (Du, Koo, Theryo, Hillmye, \& Cairncross, 2012). Davis et al. (2013) used the solution obtained by Berens and Hopfenberg (Berens \& Hopfenberg, 1978) to evaluate the mass transport parameters of the Fickian diffusion and the polymer relaxation regime. In our work, the concentration gradient and the polymer-relaxation-controlled diffusion could not be separated in all cases. Therefore, we chose to quantify the pseudo-Fickian parameters with the inverse model and to evaluate the relaxation phenomena from the difference between the pseudo-Fickian equilibrium mass uptake and the total mass uptake of the sample calculated arbitrarily after $30 \mathrm{~h}$ of sorption (at the end of the experiment).

The numerical values of the mass transport parameters are listed in Table 4. The experimental and data treatment procedures were validated by comparing the obtained effective diffusion coefficient of water in PLA with the literature data. Davis et al. (2013) obtained $\mathrm{D}=8.52 \cdot 10^{-12} \mathrm{~m}^{2} \mathrm{~s}^{-1}$ and Martinez-Sanz et al. (2012) determined $\mathrm{D}=3.63 \cdot 10^{-12} \mathrm{~m}^{2} \mathrm{~s}^{-1}$. Our value $\left(5.6 \cdot 10^{-12} \mathrm{~m}^{2} \mathrm{~s}^{-1}\right)$ is consistent with those data.

The impact of the pure CNC on the mass transfer properties of water in PLA is illustrated in Fig. 4. The results shown in Fig. 4a concern the water vapour mass uptake of the neat CNC nanocomposites. In the pseudo-Fickian part of the curves (i.e. the very beginning), the mass uptake data of all samples were more or less superposed. The quantification with the inverse model showed a small decrease in the diffusion coefficient (36 and $52 \%$ for the 2 and $6 \mathrm{wt} \%$ CNC, respectively, data in Table 4). This is consistent with the results obtained by Martinez-Sanz et al. (2012) who obtained $40 \%$ decrease for nanocomposites including $3 \mathrm{wt} \%$ bacterial CNC. Furthermore, it can be read in Table 4 that the inclusion of CNC in PLA had no impact on the pseudo-Fickian equilibrium. In contrary to that, the presence of CNC caused a clear increase in the water sorption in the polymer relaxation controlled regime. The inclusion of 2 and, a fortiori, $6 \mathrm{wt} \%$ CNC greatly increased the water mass uptake of the nanocomposites.

The evolution of the water vapour mass uptake of PLA/CNC-g-BzAA is presented in Fig. 4b and the one of PLA/CNC-g-PhAA in Fig. 4c. In the pseudo-Fickian regime, the water sorption kinetics of PLA/CNC-g-BzAA $2 \mathrm{wt} \%$ and PLA/CNC-g-PhAA $2 \mathrm{wt} \%$ were almost completely superposed on the curve of the PLA control. The calculated values showed that the effective diffusion coefficient of the nanocomposites containing CNC-g-BzAA ( $2 \mathrm{wt} \%$ ) and CNC-g-PhAA ( $2 \mathrm{wt} \%$ ) were slightly lower than the PLA blank value. The increase of the quantity of CNC-g-BzAA and CNC-g-PhAA to $6 \mathrm{wt} \%$ in PLA decreased the effective diffusion coefficient further (Table 4). The effective diffusion coefficients of PLA/ CNC-g-BzAA and PLA/CNC-g-PhAA were not much different form the ones of the PLA/CNC nanocomposites at any nanofiller concentration. More interestingly, Fig. 4 shows that the water sorption in the nonFickian diffusion regime in nanocomposites containing grafted CNC was 
Table 5

Anisole and cyclohexane mass transfer parameters.

\begin{tabular}{|c|c|c|c|c|c|c|c|}
\hline & \multirow[b]{2}{*}{ CNC (wt\%) } & \multicolumn{3}{|l|}{ Cyclohexane } & \multicolumn{3}{|l|}{ Anisole } \\
\hline & & $\mathrm{D} \times 10^{13}\left(\mathrm{~m}^{2} \mathrm{~s}^{-1}\right)$ & $\mathrm{m}_{\mathrm{eq}, \mathrm{F}}(\mathrm{wt} \%)$ & $\mathrm{P} \times 10^{22}\left(\mathrm{~kg} \mathrm{~m}^{-1} \mathrm{~s}^{-1} \mathrm{~Pa}^{-1}\right)$ & $\mathrm{D} \times 10^{15}\left(\mathrm{~m}^{2} \mathrm{~s}^{-1}\right)$ & $\mathrm{m}_{\mathrm{eq}, \mathrm{F}}(\mathrm{wt} \%)$ & $\mathrm{m}_{\mathrm{r}-120 \mathrm{~h}}(\mathrm{wt} \%)$ \\
\hline PLA & 0 & $1.7 \pm 0.8$ & $0.03 \pm 0.01$ & 8 & $3.2 \pm 1.6$ & $2.6 \pm 0.2$ & 0.7 \\
\hline PLA/CNC & 2 & $0.6 \pm 0.3$ & $0.01 \pm 0.01$ & 1 & $1.6 \pm 0.8$ & $1.4 \pm 0.2$ & 0.6 \\
\hline PLA/CNC & 6 & $1.9 \pm 1.0$ & $0.02 \pm 0.01$ & 6 & $3.7 \pm 1.8$ & $0.4 \pm 0.2$ & 0.6 \\
\hline PLA/CNC-g-PhAA & 2 & n.d. & n.d. & n.d. & $11 \pm 6$ & $0.6 \pm 0.2$ & 2.2 \\
\hline PLA/CNC-g-PhAA & 6 & n.d. & n.d. & n.d. & $3.9 \pm 2.0$ & $0.6 \pm 0.2$ & 1.0 \\
\hline PLA/CNC-g-BzAA & 2 & $0.5 \pm 0.3$ & $0.03 \pm 0.01$ & 2 & $2.5 \pm 1.3$ & $1.2 \pm 0.2$ & 0.9 \\
\hline PLA/CNC-g-BzAA & 6 & $1.1 \pm 0.6$ & $0.01 \pm 0.01$ & 2 & $8.7 \pm 4.3$ & $0.3 \pm 0.2$ & 0.2 \\
\hline
\end{tabular}

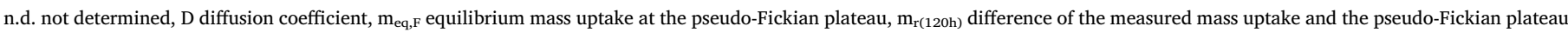
at $120 \mathrm{~h}$ attributed to Case II diffusion.

clearly smaller than that in PLA/CNC nanocomposites and the difference was significant at $6 \mathrm{wt} \%$.

To sum up, the presence of the hydrophilic CNC structures increased the water uptake of the nanocomposites in the relaxation-controlled regime, and the increase was positively correlated with of the chemical affinity of the nanofiller to water (see Table 3). Drozdov, Christiansen, Gupta, and Shah (2003) suggested that water clustering at the surface of the hydrophilic nanofillers, such as Montmorillonite clays, can cause a deceleration of diffusion but increase the sorption phenomena. Follain et al., 2013 modelled the water penetration through PCL/CNC nanocomposites with the help of a concentration-dependent diffusion coefficient. They suggested that PCL and nanocomposites PCL/CNC became plasticised by the water and that the water travelled along the interfaces. Choudalakis \& Gotsis, 2012 proposed that the presence of aggregates of nanofillers at high filling loads would increase the available free volume for penetrant sorption in polymer-depleted zones.

Putting together our results on transport properties and the morphology of the nanocomposites and the literature observations, we propose the following hypothesis: Water is present as clusters in the nanocomposites structure and there is a preferential sorption of water in the CNC/PLA interface and in the CNC, because the CNC contain some amorphous phase. In addition water would preferentially swell the CNC due to the higher chemical affinity, which allows increased water uptake in the material without much change to the effective Fickian diffusion coefficient. As the swelling of the CNC becomes significant, the water finds a preferential path of diffusion (as suggested by Follain et al., 2013) through the swollen CNC. The presence of aggregates in the $6 \mathrm{wt} \%$ CNC further increases the sorption phenomenon and mass transport due to the creation of polymer-depleted voids. Surface grafting of CNC decreases these phenomena. The improved compatibility between CNC-g-BzAA or CNC-g-PhAA with PLA decreased the occurrence of aggregates which might enclose polymerdepleted volumes. Furthermore, the more hydrophobic interface and better interface adhesion might prevent the occurrence of water clusters at the CNC/PLA interface.

\subsubsection{Anisole and cyclohexane transport in PLA/CNC nanocomposites}

The impact of the PLA/CNC interface on the mass transport properties was further probed using two organic vapours, namely, anisole and cyclohexane, which have a distinct chemical affinity to CNC, grafted CNC, and PLA (Table 3). Both cyclic molecules have a similar molar volume and cross-section (1.36 and $1.25 \mathrm{~nm}^{2}, 111.69$ and 106.75 $\AA^{3}$, for anisole and cyclohexane, respectively, dib-table 3, Espino Perez et al., 2017) but differ in their chemical functions. In particular, anisole contains an aromatic cycle and a polar group while cyclohexane does not, which explains the differences in the chemical affinity to PLA and CNC. The sorption data of cyclohexane were noisy (dib-figure 5, Espino Perez et al., 2017) due to the very small mass uptake, which was near the detection limit of the microbalance. Nevertheless, the curves could be modelled with the help of the inverse method and the Fickian diffusion behaviour was identified. At an activity of 0.2 , cyclohexane appears to be a non-swelling permeant of PLA, because, within the uncertainty of the experimental data, no polymer relaxation phenomenon was observed. Because of the small chemical affinity to CNC and grafted CNC, an absence of swelling of the nanocrystals was also assumed. Table 5 lists the corresponding diffusion coefficients and modelled Fickian equilibrium mass uptake. No significant difference was observed among the samples given the high experimental uncertainty. This illustrates the small tortuosity effect induced by the nanocrystals. An estimate of the permeability coefficient was made under the assumption of a non-concentration-dependent diffusion coefficient using the relation $\mathrm{P}=\mathrm{D} \times \mathrm{S}$. The solubility coefficient $(\mathrm{S})$ was calculated using the mass uptake corrected by the density of PLA $(\rho=1.24 \mathrm{~g} / \mathrm{mL}$ (Auras, Harte, Selke, \& Hernandez, 2003)) and the pressure gradient $\left(S=m_{e q} / \rho \Delta p\right)$. The cyclohexane permeability of the nanocomposites was lower than that of PLA. This result is essentially analogous to the observations made on oxygen permeability (Table 2).

Fig. 5 shows the sorption kinetics of anisole in PLA and its nanocomposites at 0.2 activity. All the sorption curves exhibit non-Fickian (case II) diffusion, which was expected. Aromatic molecules have high solubility in PLA and plasticising and solvent-induced crystallisation of PLA upon the sorption of benzaldehyde have been already reported (Salazar et al., 2012, 2014). Table 5 lists the effective diffusion coefficients obtained from the pseudo-Fickian part of the sorption curve, the corresponding pseudo-Fickian equilibrium mass uptake, and the mass uptake related to the non-Fickian mass uptake arbitrarily calculated at $120 \mathrm{~h}$ (end of the experiment). The effective diffusion coefficients of anisole in PLA and the nanocomposites were roughly three orders of magnitude smaller than those of the water and oxygen $\left(\mathrm{D}\left(\mathrm{O}_{2}\right)=1.8\right.$

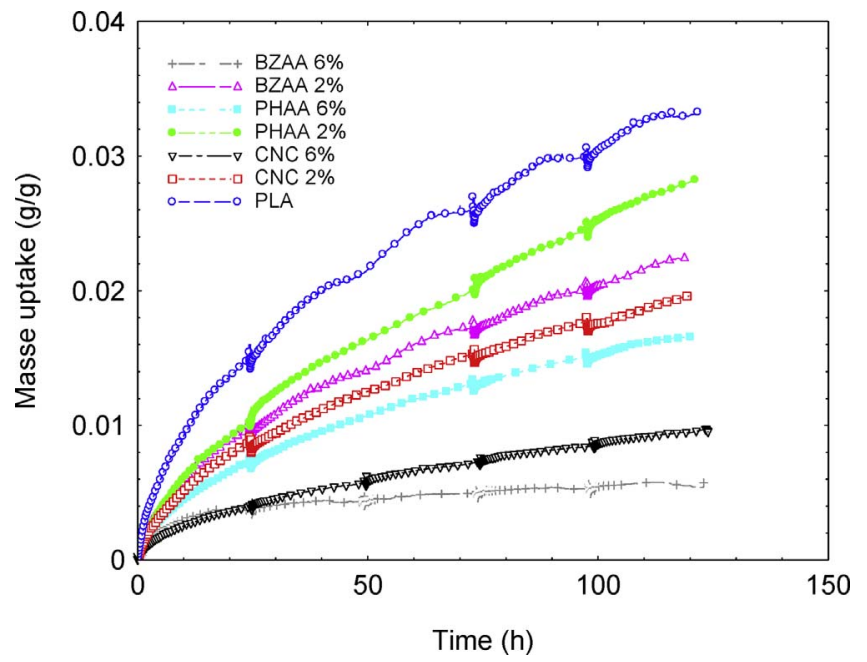

Fig. 5. Anisole sorption kinetics in nanocomposites based PLA and unmodified and modified cellulose nanocrystals at $40^{\circ} \mathrm{C}$ and anisole activity $=0.2$. 
$10^{-12} \mathrm{~m}^{2} \mathrm{~s}^{-1}$ (Guinault et al., 2012; Nassar et al., 2017)) diffusion coefficients and two orders of magnitude lower than the cyclohexane diffusion coefficients. These values fit a scaling law of diffusion coefficient versus the molecular mass of the permeant with an exponent of approximately 4 (underestimated because of the temperature difference between the different experiments). Such a scaling exponent is consistent with the identified scaling relationships for glassy polymers (Dole et al., 2006).

The anisole diffusion coefficients of the nanocomposites listed in Table 5 are not significantly different from the pure PLA value, taking into account the experimental uncertainty and fitting uncertainty due to the difficulty with uncoupling the Fickian regime from the relaxation-controlled mass transport. Globally, the small differences point to the small contribution of CNC to the tortuosity of the diffusive pathway (as already discussed). The more interesting result is that the calculated Fickian equilibrium mass uptake of all nanocomposites was much smaller than that of PLA, although CNC accounted for a relatively small volume fraction in the nanocomposite ( 2 and $5 \mathrm{vol} \%$, respectively, estimated with a density of CNC of 1.582 (Sun, 2005)). More precisely, at 2 and $6 \mathrm{wt} \% \mathrm{CNC}$, the equilibrium mass uptake of PLA/CNC-g-PhAA was higher and that of PLA/CNC-g-BzAA was lower than that of PLA/ CNC. The non-grafted CNC had no measurable impact on the polymer relaxation controlled mass uptake, CNC-g-BzAA (2 wt\%) and CNC-gPhAA ( $2 \mathrm{wt} \%)$ slightly accelerated the mass transport, CNC-g-PhAA (6 wt $\%)$ accelerated it substantially, and CNC-g-BzAA (6 wt\%) significantly decelerated it. It should also be noted that the non-Fickian mass uptake of the nanocomposites PLA/CNC-g-PhAA was higher than that of PLA/CNC-g-BzAA, although the equilibrium mass uptake of the CNC-g-PhAA powder was lower (Table 3 ).

There are thus large differences between the transport properties of water, cyclohexane, and anisole in the PLA/CNC nanocomposites. We propose that the reason for this is the different partitioning of the permeants between CNC, grafted CNC, and PLA because of their different chemical affinity to either component (Table 3). Fang et al. (2012) and Fang (2013) proposed that interfaces with a distinct chemical potential from the polymer matrix, and therefore preferential partitioning of the permeants to the surface, might act as reversible nano-absorbers in the materials. Their conclusion was that this should diminish the diffusion coefficient, but they did not examine the case of anomalous diffusion.

We think that the surface of CNC-g-BzAA or the interfacial layer with PLA preferentially takes up the permeating anisole and traps it in the interface. In our previous paper (Espino-Perez et al., 2016), we carried out the analysis of the sorption isotherms with the help of the Guggenheim-Anderson-Boer model and showed that the outer sorption layers on anisole were well structured (more so that those sorbed to $\mathrm{CNC}$ ), therefore more energy is needed for one molecule of anisole to escape the sorption layers. Due to the nano-absorber function of CNC-gBzAA, anisole would be less concentrated in the PLA phase (compared to pure PLA at the same anisole activity), which reduces the swelling phenomenon of the PLA matrix. Anisole does not swell the cellulose crystals, which created no accelerated pathway for diffusion. In conclusion, polymer relaxation phenomena are hindered by the presence of the well distributed grafted nanocrystals and less anisole is present in the amorphous phase, which overall would decrease the mass transport rate and yield an improvement of the barrier properties. Anisole, on the other hand, has equal affinity to PLA and CNC-g-PhAA, such that when CNC-g-PhAA is included in a nanocomposite, it hinders polymer swelling, but has no trapping effect.

\section{Conclusion}

The poor compatibility between CNC and PLA is a known problem in the fabrication of bionanocomposites, which can be addressed by CNC surface grafting. The rationale of this work was to test whether CNC surface grafting could serve the purpose of enhancing the compatibility of both partners and tailoring mass transport properties. Therefore, CNC was surface grafted with phenyl acetic acid and benzyl acetic acid and the mass transport parameters of $\mathrm{O}_{2}, \mathrm{H}_{2} \mathrm{O}$ vapour (high chemical affinity to $\mathrm{CNC}$ ), cyclohexane vapour (low chemical affinity to either surface grafted $\mathrm{CNC}$ ), and anisole vapour (high chemical affinity to CNC modified with benzyl acetic acid) were analysed. The vapours anisole and $\mathrm{H}_{2} \mathrm{O}$ showed non-Fickian, Case II mass transport behaviour. The less interacting permeants, namely, $\mathrm{O}_{2}$ and cyclohexane, showed Fickian mass transport behaviour and exhibited the small tortuosity effect to be expected from CNC and surface-grafted CNC. The analysis of the polymer relaxation controlled mass transport regime showed that water swelled the CNC charges, which significantly increased the water solubility in the system and produced a preferential pathway for water transport through the nanocomposites. The surface grafting of CNC successfully attenuated the effect, but without completely eliminating it. The CNC grafted with benzyl acetic acid had apparently a specific trapping effect on anisole, which seemed to yield permeant accumulation in the CNC/PLA interface but without swelling CNC and without creating a preferential diffusion pathway. This finding might open a new way for designing specific barrier properties by tailoring nanocomposite interfaces to trap chosen permeants. It could be applied to a number of situations, where a specific barrier to a class of molecules is required. One example might be the barrier against aroma constituents that are difficult to obtain, but are important in the food and cosmetics industry.

\section{Acknowledgements}

This work was supported by the Mexican Scholarship Council (CONACyT) under grant No. 213840. We thank Alain Guinault(CNAM, UMR PIMM, Paris) for his help in the determination of the oxygen permeability properties of the film samples.

\section{References}

Ahmad, E. E. M., \& Luyt, A. S. (2012). Morphology, thermal, and dynamic mechanical properties of poly(lactic acid)/sisal whisker nanocomposites. Polymer Composites, 33(6), 1025-1032.

Arrieta, M. P., Fortunati, E., Dominici, F., Rayon, E., Lopez, J., \& Kenny, J. M. (2014) Multifunctional PLA-PHB/cellulose nanocrystal films: processing: Structural and thermal properties. Carbohydrate Polymers, 107, 16-24.

Auras, R. A., Harte, B., Selke, S., \& Hernandez, R. (2003). Mechanical, Physical, and Barrier Properties of Poly(Lactide) Films. Journal of Plastic Film and Sheeting, 19(2), $123-135$.

Azizi, S., My, A. S., Alloin, F., \& Dufresne, A. (2005). Review of recent research into cellulosic whiskers, their properties and their application in nanocomposite field. Biomacromolecules, 6(2), 612-626.

Bandyopadhyay, P., Park, W. B., Layek, R. K., Uddin, M. E., Kim, N. H., Kim, H.-G., et al. (2016). Hexylamine functionalized reduced graphene oxide/polyurethane nanocomposite-coated nylon for enhanced hydrogen gas barrier film. Journal of Membrane Science, 500, 106-114.

Berens, A. R., \& Hopfenberg, H. B. (1978). Diffusion and relaxation in glassy polymer powders .2. Separation of diffusion and relaxation parameters. Polymer, 19(5), 489-496.

Bordes, P., Pollet, E., \& Averous, L. (2009). Nano-biocomposites: Biodegradable polyester/nanoclay systems. Progress in Polymer Science, 34(2), 125-155.

Charlon, S., Follain, N., Chappey, C., Dargent, E., Soulestin, J., Sclavons, M., et al. (2015). Improvement of barrier properties of bio-based polyester nanocomposite membranes by water-assisted extrusion. Journal of Membrane Science, 496, 185-198.

Choudalakis, G., \& Gotsis, A. D. (2009). Permeability of polymer/clay nanocomposites: A review. European Polymer Journal, 45(4), 967-984.

Choudalakis, G., \& Gotsis, A. D. (2012). Free volume and mass transport in polymer nanocomposites. Current Opinion in Colloid \& Interface Science, 17(3), 132-140.

Clemenson, S., Espuche, E., David, L., \& Leonard, D. (2010). Nanocomposite membranes of polyetherimide nanostructured with palladium particles: Processing route, morphology and functional properties. Journal of Membrane Science, 361(1-2), 167-175.

Colomines, G., Domenek, S., Ducruet, V., \& Guinault, A. (2008). Influences of the crystallisation rate on thermal and barrier properties of polylactide acid (PLA) food packaging films. International Journal of Material Forming, 1, 607-609.

Courgneau, C., Domenek, S., Guinault, A., Averous, L., \& Ducruet, V. (2011). Analysis of the structure-properties relationships of different multiphase systems based on plasticized poly(lactic acid). Journal of Polymers and the Environment, 19(2), 362-371.

Davis, E. M., \& Elabd, Y. A. (2013). Prediction of water solubility in glassy polymers using nonequilibrium thermodynamics. Industrial \& Engineering Chemistry Research, 52(36), $12865-12875$. 
Davis, E. M., Minelli, M., Baschetti, M. G., Sarti, G. C., \& Elabd, Y. A. (2012). Nonequilibrium sorption of water in polylactide. Macromolecules, 45(18), 7486-7494.

Davis, E. M., Minelli, M., Baschetti, M. G., \& Elabd, Y. A. (2013). Non-Fickian diffusion of water in polylactide. Industrial \& Engineering Chemistry Research, 52(26), 8664-8673.

Delpouve, N., Stoclet, G., Saiter, A., Dargent, E., \& Marais, S. (2012). Water barrier properties in biaxially drawn poly(lactic acid) films. Journal of Physical Chemistry B, 116(15), 4615-4625.

Dobircau, L., Delpouve, N., Herbinet, R., Domenek, S., Le Pluart, L., Delbreilh, L., et al. (2015). Molecular mobility and physical ageing of plasticized poly(lactide). Polymer Engineering \& Science, 55, 858-865.

Dole, P., Feigenbaum, A. E., De la Cruz, C., Pastorelli, S., Paseiro, P., Hankemeier, T., et al. (2006). Typical diffusion behaviour in packaging polymers - application to functional barriers. Food Additives and Contaminants, 23(2), 202-211.

Drozdov, A. D., Christiansen, J. D., Gupta, R. K., \& Shah, A. P. (2003). Model for anomalous moisture diffusion through a polymer-clay nanocomposite. Journal of Polymer Science Part B-Polymer Physics, 41(5), 476-492.

Du, A., Koo, D., Theryo, G., Hillmyer, M. A., \& Cairncross, R. A. (2012). Water transport and clustering behavior in homopolymer and graft copolymer polylactide. Journal of Membrane Science, 396, 50-56.

Duan, Z., Thomas, N. L., \& Huang, W. (2013). Water vapour permeability of poly(lactic acid) nanocomposites. Journal of Membrane Science, 445, 112-118.

Ducruet, V., \& Domenek, S. (2015). Characteristics and applications of poly(lactic acid). In S. Kalia, \& L. Averous (Eds.). Biodegradable and bio-based polymers: environmental and biomedical applications (pp. 171-224). Beverly, MA: Scrivener Publishing LLC.

Espino Perez, E., Bras, J., Almeida, G., Plessis, C., Belgacem, M. N., Perre, P., et al. (2017). Designed cellulose nanocrystal surface properties for improving barrier properties in polylactide nanocomposites. http://dx.doi.org/10.1016/j.carbpol.2017.12.005.

Espino-Perez, E., Bras, J., Ducruet, V., Guinault, A., Dufresne, A., \& Domenek, S. (2013). Influence of chemical surface modification of cellulose nanowhiskers on thermal, mechanical, and barrier properties of poly(lactide) based bionanocomposites. European Polymer Journal, 49(10), 3144-3154.

Espino-Perez, E., Domenek, S., Belgacem, N., Sillard, C., \& Bras, J. (2014). Green process for chemical functionalization of nanocellulose with carboxylic acids. Biomacromolecules, 15(12), 5441-5460.

Espino-Perez, E., Bras, J., Almeida, G., Relkin, P., Belgacem, N., Plessis, C., et al. (2016). Cellulose nanocrystal surface functionalization for the controlled sorption of water and organic vapours. Cellulose, 23(5), 2955-2970.

Fang, X., Vitrac, O., Domenek, S., \& Ducruet, V. (2012). Controlling the molecular interactions to improve the diffusion barrier of biosourced polymers to organic solutes. Defect and Diffusion Forum, 323-325.

Fang, X. (2013). Conception raisonnée de matériaux barrière incorporant des nano-adsorbants (Design of barrier materials with nano-absorbants). p. 319PhD Thesis in Sciences et Procédés des Aliments et Bioproduits. Paris, France: AgroParisTech.

Follain, N., Belbekhouche, S., Bras, J., Siqueira, G., Marais, S., \& Dufresne, A. (2013). Water transport properties of bio-nanocomposites reinforced by Luffa cylindrica cellulose nanocrystals. Journal of Membrane Science, 427, 218-229.

Fortunati, E., Luzi, F., Jiménez, A., Gopakumar, D. A., Puglia, D., Thomas, S., et al. (2016). Revalorization of sunflower stalks as novel sources of cellulose nanofibrils and nanocrystals and their effect on wheat gluten bionanocomposite properties. Carbohydrate Polymers, 149, 357-368.

Fortunati, E., Gigli, M., Luzi, F., Dominici, F., Lotti, N., Gazzano, M., et al. (2017) Processing and characterization of nanocomposite based on poly(butylene/triethylene succinate) copolymers and cellulose nanocrystals. Carbohydrate Polymers, 165, 51-60.

Fortunati, E., Armentano, I., Zhou, Q., Iannoni, A., Saino, E., Visai, L., et al. (2012). Multifunctional bionanocomposite films of poly(lactic acid), cellulose nanocrystals and silver nanoparticles. Carbohydrate Polymers, 87(2), 1596-1605.

Fortunati, E., Peltzer, M., Armentano, I., Torre, L., Jimenez, A., \& Kenny, J. M. (2012). Effects of modified cellulose nanocrystals on the barrier and migration properties of PLA nano-biocomposites. Carbohydrate Polymers, 90(2), 948-956.

Ganesan, V., Ellison, C. J., \& Pryamitsyn, V. (2010). Mean-field models of structure and dispersion of polymer-nanoparticle mixtures. Soft Matter, 6(17), 4010-4025.

Guinault, A., Sollogoub, C., Ducruet, V., \& Domenek, S. (2012). Impact of crystallinity of poly(lactide) on helium and oxygen barrier properties. European Polymer Journal, 48(4), 779-788.

Hall, L. M., \& Schweizer, K. S. (2010). Structure, scattering patterns and phase behavior of polymer nanocomposites with nonspherical fillers. Soft Matter, 6(5), 1015-1025.

Hanson, B., Pryamitsyn, V., \& Ganesan, V. (2012). Computer simulations of gas diffusion in polystyrene-C-60 fullerene nanocomposites using trajectory extending kinetic monte carlo method. Journal of Physical Chemistry B, 116(1), 95-103.

Huang, H.-D., Ren, P.-G., Xu, J.-Z., Xu, L., Zhong, G.-J., Hsiao, B. S., et al. (2014). Improved barrier properties of poly(lactic acid) with randomly dispersed graphene oxide nanosheets. Journal of Membrane Science, 464(0), 110-118.

Karayiannis, N. C., Mavrantzas, V. G., \& Theodorou, D. N. (2001). Diffusion of small molecules in disordered media: Study of the effect of kinetic and spatial heterogeneities. Chemical Engineering Science, 56(8), 2789-2801.

Krishnamoorti, R., \& Vaia, R. A. (2007). Polymer nanocomposites. Journal of Polymer Science Part B: Polymer Physics, 45(24), 3252-3256.

Lee, J. H., Park, S. H., \& Kim, S. H. (2013). Preparation of cellulose nanowhiskers and their reinforcing effect in polylactide. Macromolecular Research, 21(11), 1218-1225.

Luo, J. J., \& Daniel, I. M. (2003). Characterization and modeling of mechanical behavior of polymer/clay nanocomposites. Composites Science and Technology, 63(11), 1607-1616.

Mariano, M., El Kissi, N., \& Dufresne, A. (2016). Cellulose nanocrystal reinforced oxidized natural rubber nanocomposites. Carbohydrate Polymers, 137, 174-183.

Martinez-Sanz, M., Lopez-Rubio, A., \& Lagaron, J. M. (2012). Optimization of the dispersion of unmodified bacterial cellulose nanowhiskers into polylactide via melt compounding to significantly enhance barrier and mechanical properties. Biomacromolecules, 13(11), 3887-3899.

Martino, V. P., Ruseckaite, R. A., \& Jiménez, A. (2009). Ageing of poly(lactic acid) films plasticized with commercial polyadipates. Polymer International, 58, 437-444.

Minelli, M., Baschetti, M. G., Doghieri, F., Ankerfors, M., Lindström, T., Siró, I., et al. (2010). Investigation of mass transport properties of microfibrillated cellulose (MFC) films. Journal of Membrane Science, 358(1-2), 67-75.

Nassar, S. F., Guinault, A., Delpouve, N., Divry, V., Ducruet, V., Sollogoub, C., et al (2017). Multi-scale analysis of the impact of polylactide morphology on gas barrier properties. Polymer, 108, 163-172.

Pan, P. J., Zhu, B., \& Inoue, Y. (2007). Enthalpy relaxation and embrittlement of poly(Llactide) during physical aging. Macromolecules, 40(26), 9664-9671.

Perre, P., \& Turner, I. W. (1999). A 3-D version of TransPore: A comprehensive heat and mass transfer computational model for simulating the drying of porous media. International Journal of Heat and Mass Transfer, 42(24), 4501-4521.

Perre, P., Pierre, F., Casalinho, J., \& Ayouz, M. (2015). Determination of the mass diffusion coefficient based on the relative humidity measured at the back face of the sample during unsteady regimes. Drying Technology, 33(9), 1068-1075.

Press, W. H., Teukolski, S. A., Vetterling, W. T., \& Flannery, B. P. (1992). Numerical recipes in FORTRAN - The art of scientific computing (2nd ed.). Cambridge, UK: Cambridge University Press.

Rhim, J. W., Park, H. M., \& Ha, C. S. (2013). Bio-nanocomposites for food packaging applications. Progress in Polymer Science, 38(10-11), 1629-1652.

Rusli, R., Shanmuganathan, K., Rowan, S. J., Weder, C., \& Eichhorn, S. J. (2010). Stresstransfer in anisotropic and environmentally adaptive cellulose whisker nanocomposites. Biomacromolecules, 11(3), 762-768.

Salazar, R., Domenek, S., Courgneau, C., \& Ducruet, V. (2012). Plasticization of poly (lactide) by sorption of volatile organic compounds at low concentration. Polymer Degradation and Stability, 97(10), 1871-1880.

Salazar, R., Domenek, S., \& Ducruet, V. (2014). Interactions of flavoured oil in-water emulsions with polylactide. Food Chemistry, 148(0), 138-146.

Sanchez-Garcia, M., \& Lagaron, J. (2010). On the use of plant cellulose nanowhiskers to enhance the barrier properties of polylactic acid. Cellulose, 17(5), 987-1004.

Sanchez-Garcia, M. D., Gimenez, E., \& Lagaron, J. M. (2008). Morphology and barrier properties of solvent cast composites of thermoplastic biopolymers and purified cellulose fibers. Carbohydrate Polymers, 71(2), 235-244.

Stark, N. M. (2016). Opportunities for cellulose nanomaterials in packaging films: A review and future trends. Journal of Renewable Materials, 4(5), 313-326.

Sun, C. (2005). True density of microcrystalline cellulose. Journal of Pharmaceutical Sciences, 94(10), 2132-2134.

Sung, S. H., Chang, Y., \& Han, J. (2017). Development of polylactic acid nanocomposite films reinforced with cellulose nanocrystals derived from coffee silverskin. Carbohydrate Polymers, 169, 495-503.

Tan, B., \& Thomas, N. L. (2016). A review of the water barrier properties of polymer/clay and polymer/graphene nanocomposites. Journal of Membrane Science, 514, 595-612.

Vitrac, O., \& Hayert, M. (2007). Effect of the distribution of sorption sites on transport diffusivities: A contribution to the transport of medium-weight-molecules in polymeric materials. Chemical Engineering Science, 62(9), 2503-2521.

Yu, H.-Y., Yang, X.-Y., Lu, F.-F., Chen, G.-Y., \& Yao, J.-M. (2016). Fabrication of multifunctional cellulose nanocrystals/poly(lactic acid) nanocomposites with silver nanoparticles by spraying method. Carbohydrate Polymers, 140, 209-219. 
Data article

Title: Designed cellulose nanocrystal surface properties for improving barrier properties in polylactide nanocomposites

Authors: Etzael Espino-Pérez, ${ }^{+, \neq}$Julien Bras, ${ }^{\dagger, \S}$ Giana Almeida, ${ }^{\ddagger}$ Cédric Plessis, ${ }^{\ddagger}$ Naceur Belgacem, ${ }^{\dagger, \S}$ Patrick Perré, ${ }^{\#}$ Sandra Domenek ${ }^{\ddagger}{ }^{*}$

Affiliations:

${ }^{\dagger}$ University Grenoble Alpes, LGP2, F-38000 Grenoble, France

${ }^{\ddagger}$ UMR Ingénierie Procédés Aliments, AgroParisTech, INRA, Université Paris Saclay, F-91300 Massy, France

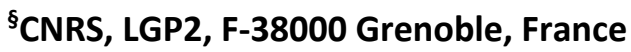

${ }^{\#}$ Ecole Centrale Paris, LGPM, F-92290 Chatenay Malabry, France

Contact email: sandra.domenek@agroparistech.fr

\begin{abstract}
The present article presents a mass transport study in polylactide (PLA) nanocomposites including cellulose nanocrystals (CNC) with specifically designed surface. The objective is to show the impact of the nanofiller/polymer matrix interface on mass transport parameters. The chemical affinity of the CNC surface to the probe molecules (water, anisole, cyclohexane) was varied by surface grafting with different aromatic molecules. The morphology and the thermal stability of the different PLA/CNC nanocomposites were described. The raw data of the mass transport and their modeling with the recently developed inverse model are presented. This shows that the mass transport has largely non-Fickian character and that the applied modeling procedure was able to isolate the underlying Fickian transport parameters.

The importance of the phenomenon of non-Fickian mass transport was a function of the specific interactions between the permeant molecule, the CNC surface and the polymer matrix. High non-Fickian mass uptake could be related either to high affinity of the penetrant to aggregates of CNC or to the PLA Further interpretation and quantification of the data can be found in the associated research article (Espino et al., Carbohydrate Polymers 2018, 183, 267277.).
\end{abstract}


Specifications Table

\begin{tabular}{|l|l|}
\hline Subject area & Physics, Chemistry, Polymers, Nanocomposites, Mass Transport \\
\hline More specific subject area & Biodegradable and biobased nanocomposites, non-Fickian Mass transport \\
\hline Type of data & Tables, images (microscopy), graphs (sorption curves) \\
\hline How data was acquired & $\begin{array}{l}\text { Photography (hand held standard camera), thermogravimetric analysis } \\
\text { (TGA Q500 TA Instruments), literature review }\end{array}$ \\
\hline Data format & Raw and modeled analyzed \\
\hline Experimental factors & $\begin{array}{l}\text { The grafting of CNC was carried out by applying the SolReact method } \\
\text { (Espino-Perez, Domenek, Belgacem, Sillard \& Bras, 2014). The } \\
\text { nanocomposites were fabricated by the casting procedure from CHCl } 3 \\
\text { solution. }\end{array}$ \\
\hline Experimental features & $\begin{array}{l}\text { Thermal degradation analysis of PLA and nanocomposites was carried out } \\
\text { with a TGA Q500 (TA Instruments). Water sorption experiments were } \\
\text { carried with a DVS microbalance. Sorption curves of cyclohexane and were } \\
\text { recorded with a IGA microbalance. }\end{array}$ \\
\hline Data source location & $\begin{array}{l}\text { Massy, France } \\
\text { Data in this article is supporting the research article of Espino et al., } \\
\text { Carbohydrate Polymers 2018, 183, 267-277. }\end{array}$ \\
\hline
\end{tabular}


Value of the data

- CNC surface grafting with aromatic molecules increases its compatibility with PLA

- Surface grafted CNC are homogenously dispersed in the PLA matrix

- The inverse modeling method can successfully separate Fickian and non-Fickian mass transport

- Dispersion of neat CNC inside the PLA matrix increases water mass transport in the nonFickian regime

- CNC surface grafting impacts the water mass transport properties in the non-Fickian regime by decreasing the polymer relaxation phenomenon

- CNC surface grafting with aromatic molecules does not impact cyclohexane mass transport because of low interaction between cyclohexane and aromatic moieties

- CNC surface grafting with aromatic molecules successfully decreases the non-Fickian mass transport of aromatic molecules due to a trapping effect in the interface region

\section{Data}

The presented data form part of a mass transport study of polymer nanocomposites with a designed nanofiller/polymer matrix interface. For that, PLA/CNC nanocomposites with different CNC surface chemistry were prepared using the casting method followed by thermal molding. The morphology of the nanocrystals and the thermal stability of the nanocomposites were probed. Furthermore, the macroscopic dispersion quality of the CNC inside the PLA matrix is shown. The study of the mass transport was done by sorption experiments with the help of microbalances. Different probe molecules with varying chemical affinity to CNC or PLA were used. Water vapor has high affinity to neat CNC, anisole has high affinity to PLA and to the surface grafted CNC, while cyclohexane had comparable molecular dimensions to anisole but low chemical affinity to CNC and PLA. The data show the raw sorption curves and their description by a recently developed model, able to discriminate Fickian and non-Fickian mass transport.

\section{Description of the PLA/CNC nanocomposites}

The surface functionalization of CNC was done using the SolReact technique, developed by(Espino-Perez, Domenek, Belgacem, Sillard \& Bras, 2014). This method consists in a surface esterification by using the carboxylic acid as the liquid for the suspension of the CNC at a temperature higher than $100^{\circ} \mathrm{C}$ for continuous distillation of water molecules. The figure 1 shows the chemical structures of the surface grafted CNC. This procedure allowed maintaining the physical dimensions of the CNC, which are given in table 2. Those data were used for the calculation of the percolation threshold of CNC in the nanocomposite. 

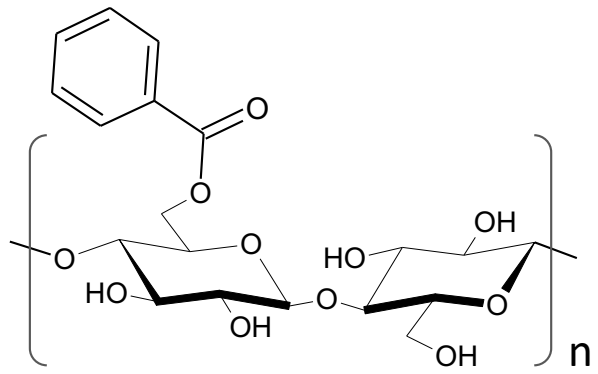

CNC-g-PhAA

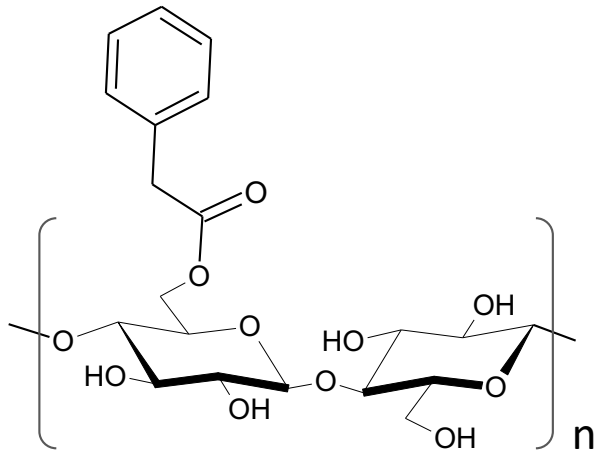

CNC-g-BzAA

Figure 1. Chemical structure of the phenyl acetic acid (PhAA) and benzyl acetic acid (BzAA) grafted on the CNC surface.

The nanocomposites of PLA and CNC, CNC-g-PhAA, and CNC-g-BzAA were fabricated using the solvent casting method using chloroform followed by a hot-molding step in a heating press at $180^{\circ} \mathrm{C}$. The step at high temperature was necessary to eliminate the residual solvent and to obtain of samples with controlled thickness. Thorough control of the sample thickness was important, because the mass transport parameters, in particular the diffusion coefficient, can only be obtained when the sample geometry is known. The heating protocol was optimized with regards to the thermal stability of the PLA nanocomposites. The thermal degradation data were recorded with a TGA Q500 (TA Instruments) at a heating rate of $10^{\circ} \mathrm{C} / \mathrm{min}$ under $\mathrm{N}_{2}$ atmosphere. The table 1 shows the results of PLA and its nanocomposites. In any case the temperature of the hot-molding process was below the thermal degradation temperature of the samples.

Table 1. Thermal degradation parameters of PLA and PLA/CNC nanocomposites: degradation temperature at maximum degradation rate and degraded weight at $600{ }^{\circ} \mathrm{C}$

\begin{tabular}{cccccc}
\hline \multirow{2}{*}{ Sample } & \multicolumn{2}{c}{ Degradation temperature $\left({ }^{\circ} \mathrm{C}\right)$} & \multicolumn{2}{c}{ Degraded weight (\%) } \\
\cline { 2 - 6 } & $2 \mathrm{wt} \%$ & $6 \mathrm{wt} \%$ & $2 \mathrm{wt} \%$ & $6 \mathrm{wt} \%$ \\
\hline PLA & \multicolumn{3}{c}{324} & & 98 \\
PLA/CNC & 303 & 308 & 98 & 95 \\
\hdashline PLA/CNC-g-PhAA & 324 & 325 & 97 & 96 \\
PLA/CNC-g-BzAA & 324 & 324 & 98 & 97 \\
\hline
\end{tabular}

Table 2. Geometric dimensions of CNC and grafted CNC.

\begin{tabular}{lccc}
\multicolumn{1}{c}{ Sample } & $\mathrm{I}(\mathrm{nm})^{*}$ & $\mathrm{~d}(\mathrm{~nm})^{*}$ & $v_{P}(\mathrm{wt} \%)$ \\
& & & \\
\hline CNC & $155 \pm 43$ & $17 \pm 5$ & $8 \pm 3$ \\
CNC-g-PhAA & $131 \pm 36$ & $10 \pm 2$ & $6 \pm 2$ \\
CNC-g-BzAA & $145 \pm 52$ & $13 \pm 3$ & $5 \pm 2$ \\
\hline
\end{tabular}


*Data published (Espino-Perez, Domenek, Belgacem, Sillard \& Bras, 2014)

The photographs in Figure 3 show the dispersion efficiency of the CNC and the surface grafted CNC in the PLA nanocomposites. In the Figure 3a, which pictures the PLA/CNC composites, large aggregates of CNC can be observed. In contrary, the PLA/CNC-g-BzAA nanocomposites were transparent even at 6 wt\% of nanofiller. This shows the decrease of CNC aggregation in the PLA matrix due to the compatibilizer effect of the surface graft.

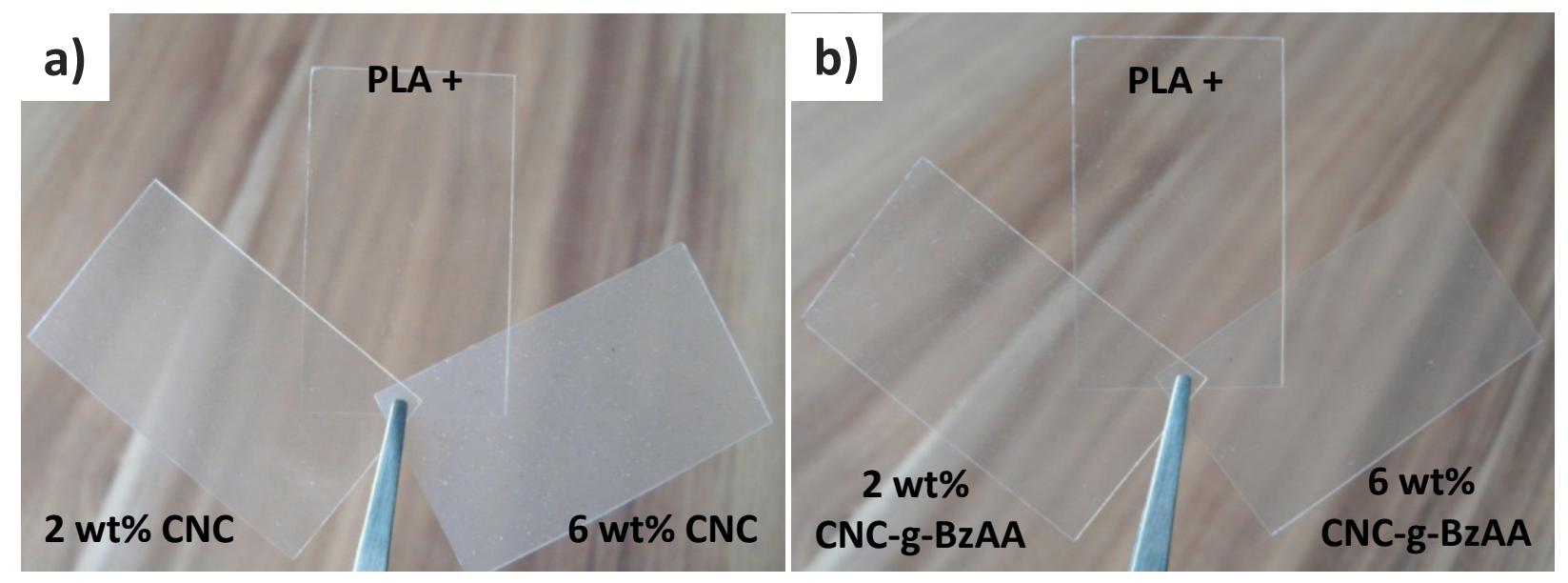

Figure 3. Photographs of PLA/CNC nanocomposites produced by the casting method. In the figure a are shown the photos of neat CNC nanocomposites and in the photo $b$ CNC grafted with hydrocinnamic acid (CNC-g-BzAA).

\section{Description of the experimental system for the analysis of mass transport}

The water vapor sorption experiments were performed with a DVS microbalance (Surface Measurement Systems, London, UK). The principle of the measurement is the recording of the mass uptake of the samples, which are suspended in an atmosphere at controlled relative humidity $(\mathrm{RH})$ and ambient pressure. The measurement temperature was at $25^{\circ} \mathrm{C}$. The samples were rejuvenated before analysis by a brief thermal treatment above the glass transition temperature of PLA ( $30 \mathrm{~min}$ at $60{ }^{\circ} \mathrm{C}$ ). Then, the samples were equilibrated in the DVS apparatus at $0 \%$ relative humidity $(\mathrm{RH})$ during $360 \mathrm{~min}$. The amount of dry matter was determined at the end of this plateau. Subsequently, the RH was increased to $30 \%$ and maintained at this level for 1440 min. Finally, the RH was increased to $90 \%$ and maintained at this level for $2880 \mathrm{~min}$.

The sorption curves of cyclohexane and were recorded with the help of an IGA microbalance (Hiden Isochema, Warrington, UK) at $40^{\circ} \mathrm{C}$ and $0 \% \mathrm{RH}$. This microbalance works at low pressure, where the sample is suspended in an atmosphere at a given partial pressure of the probe molecule. The mass uptake of the samples was recorded automatically over 5 days. The results of the preliminary experiments showed that there is some inevitable leakage past the copper seals, which, over time, leads to the dilution of the organic vapours by incoming air. Therefore, a pressure perturbation was introduced at regular time intervals to ensure a constant partial pressure while the measurement was being performed. This pressure perturbation forces the electronics of the microbalance to re-regulate the partial pressure by pumping part of the atmosphere in the chamber and re-regulating by connecting 
the organic vapour reservoir. It is the origin of the spikes observed in the raw data of the sorption curves. For analysis, these spikes were cancelled. The table 3 recalls some important parameter of the organic molecules anisole and cyclohexane used for the mass transport studies.

Table 3. Physicochemical properties of the anisole and cyclohexane.

\begin{tabular}{ccccccc}
\hline & $\begin{array}{c}\mathrm{M} \\
\left(\mathrm{g} \mathrm{mol}^{-1}\right)\end{array}$ & $\begin{array}{c}\mathrm{S} \\
\left(\mathrm{nm}^{2}\right)\end{array}$ & $\begin{array}{c}\mathrm{V}_{\text {mol }} \\
\left(\AA^{3}\right)\end{array}$ & $\begin{array}{c}\mathrm{BP} \\
\left({ }^{\circ} \mathrm{C}\right)\end{array}$ & $\begin{array}{c}P_{s v} \text { at } 40^{\circ} \mathrm{C} \\
(\mathrm{Pa})\end{array}$ & $\begin{array}{c}P_{v} \text { at activity }= \\
0.2(\mathrm{~Pa})\end{array}$ \\
\hline Anisole & 108.14 & 1.36 & 111.69 & 154 & 1148.8 & 229.8 \\
Cyclohexane & 84.16 & 1.25 & 106.75 & 81 & 24776.7 & 4955.3 \\
\hline
\end{tabular}

The modelling of the mass transport was carried out with the help of the adapted inverse transport model presented by (Perre, Pierre, Casalinho \& Ayouz, 2015). The mathematical development can be found in (Espino-Pérez et al., 2018). The Figure 2 below shows an analysis of a DVS water vapour sorption kinetics.

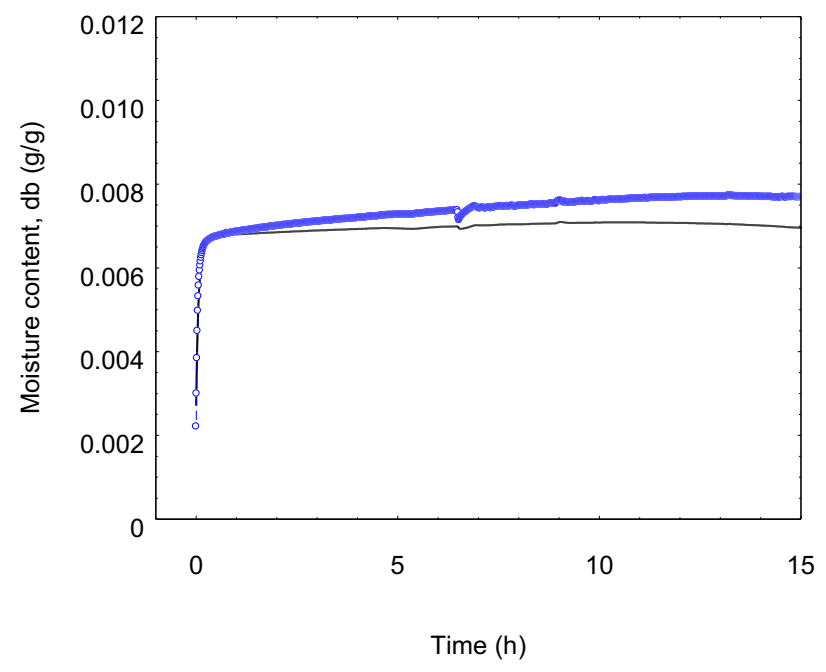

Figure 2. Confrontation of experimental data (blue line) and model fit for Fickian diffusion (black line) for water sorption of PLA at $90 \% \mathrm{RH}$ and $25{ }^{\circ} \mathrm{C}$ done with a DVS apparatus.

\section{Data on mass transport studies}

The raw data of the different mass transport experiments and the modelling with the help of the inverse transport model are shown in the following. The figure 4 plots typical raw water vapour sorption curves (blue lines) and the modelling of the Fickian mass transport regime (red lines). The water transport in PLA was characterized by an initial Fickian, and a subsequent non-Fickian, polymer relaxation controlled regime (Fig. 4a). The increase of the weight percentage of neat CNC in the PLA nanocomposites increased the non-Fickian transport part (Fig. $4 \mathrm{~b}$ and $4 \mathrm{c}$ vs. $4 \mathrm{a}$ ). The surface grafting of the CNC decreased the non-Fickian transport in the nanocomposites (Fig. 4b, 4c vs. 4d, 4e, 4f, 4g). 


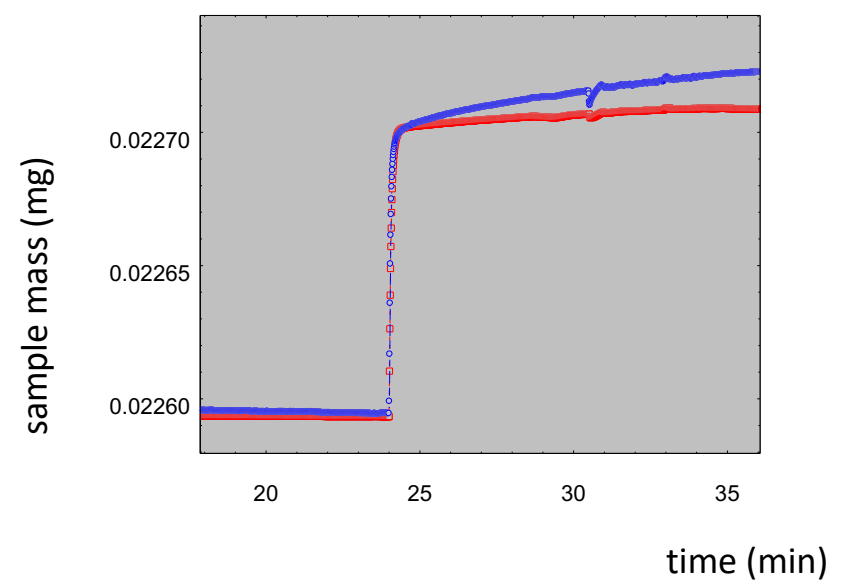

a. Water mass uptake in PLA

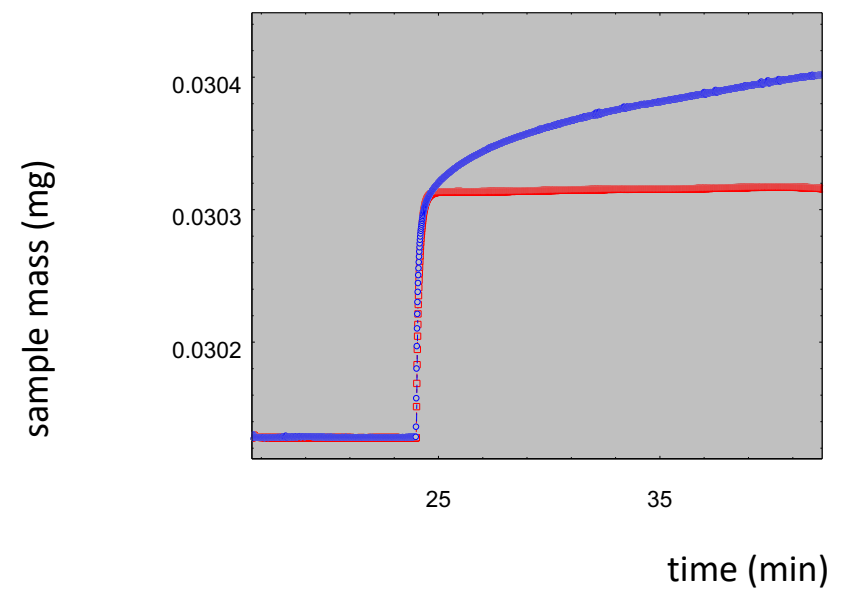

b. Water mass uptake in PLA/CNC $2 \%$

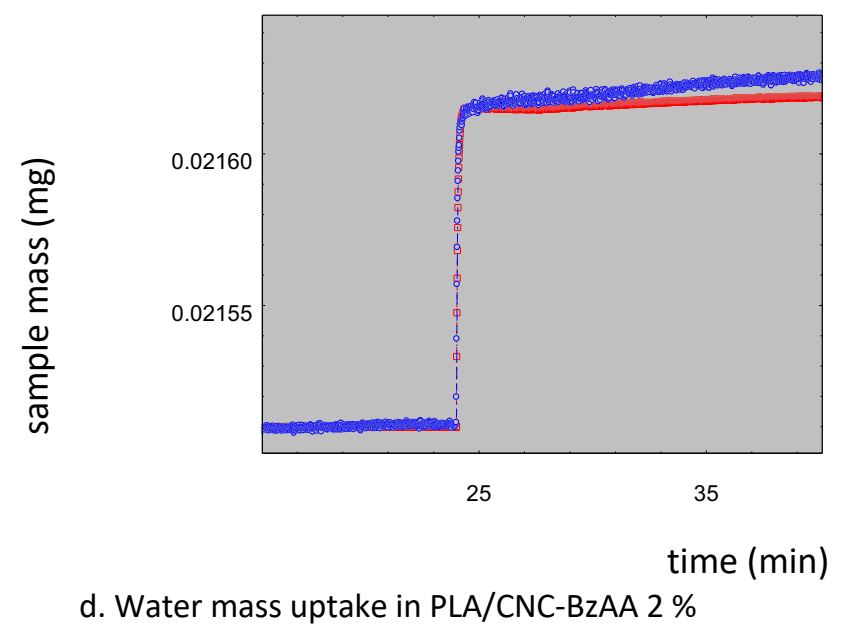

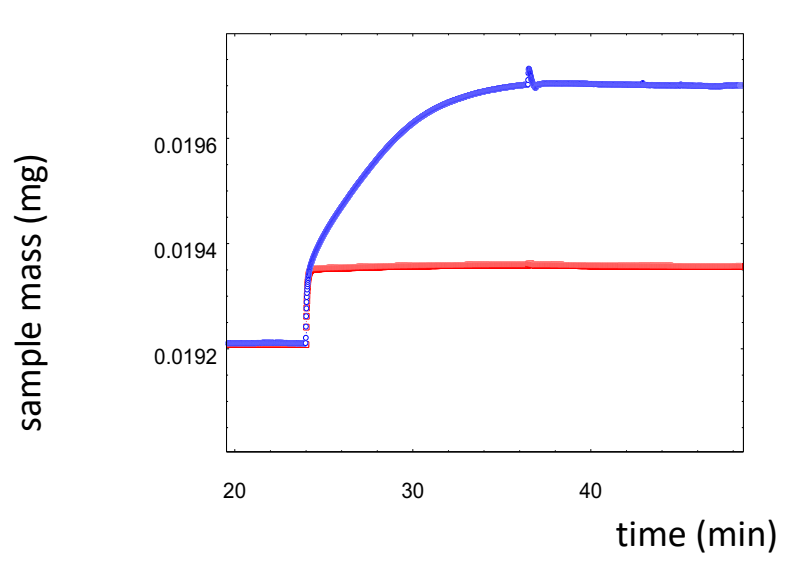

c. Water mass uptake in PLA/CNC $6 \%$

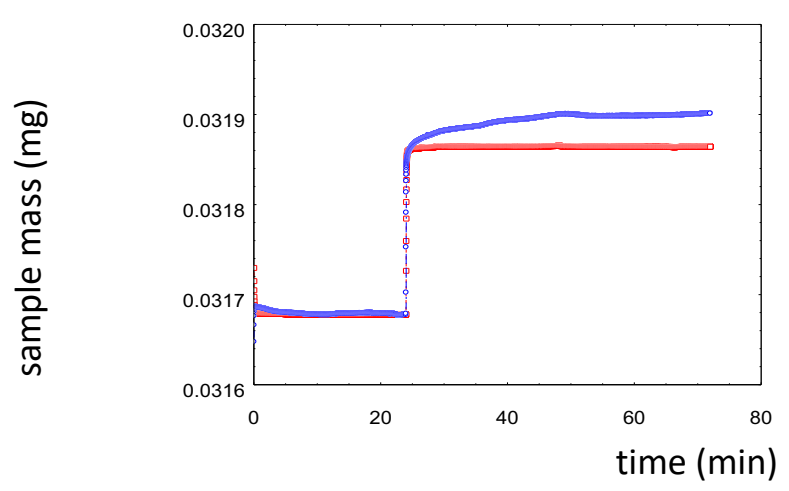

e. Water mass uptake in PLA/CNC-BzAA $6 \%$ 


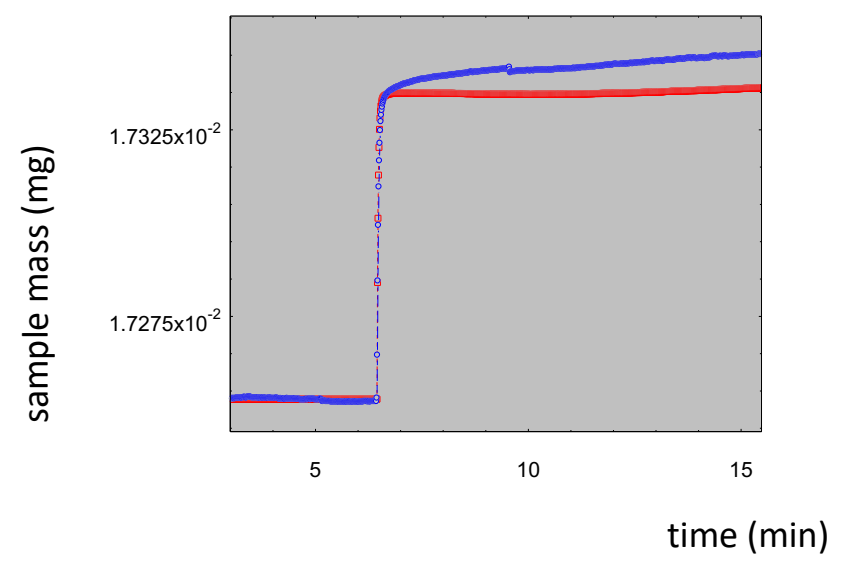

f. Water mass uptake in PLA/CNC-PhAA $2 \%$

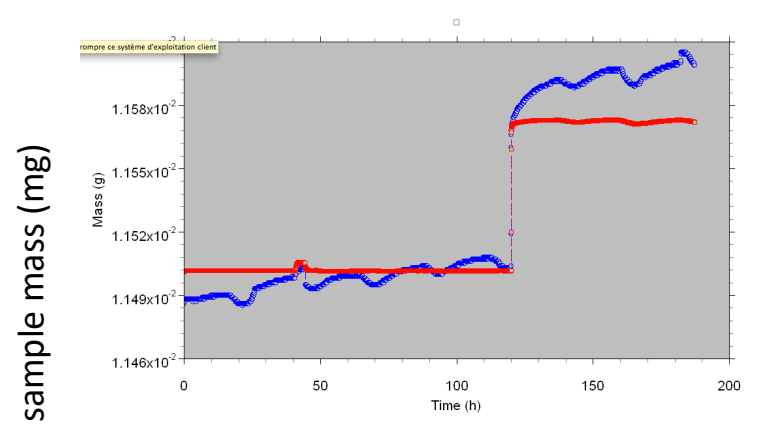

. Water mass uptake in PLA/CNC-PhAA $6 \%$

Figure 4. Raw data of the DVS water sorption experiments (blue lines) and modelled data of the Fickian mass transport with the inverse transport model (red lines).

The figure 5 shows the sorption curves of the cyclohexane mass uptake, which was close to the sensitivity limit of the microbalance. Therefore, the data were noisy. The solid lines correspond to the model curves obtained by the inverse method of the Fickian mass transport regime. No non-Fickian transport regime was observed.

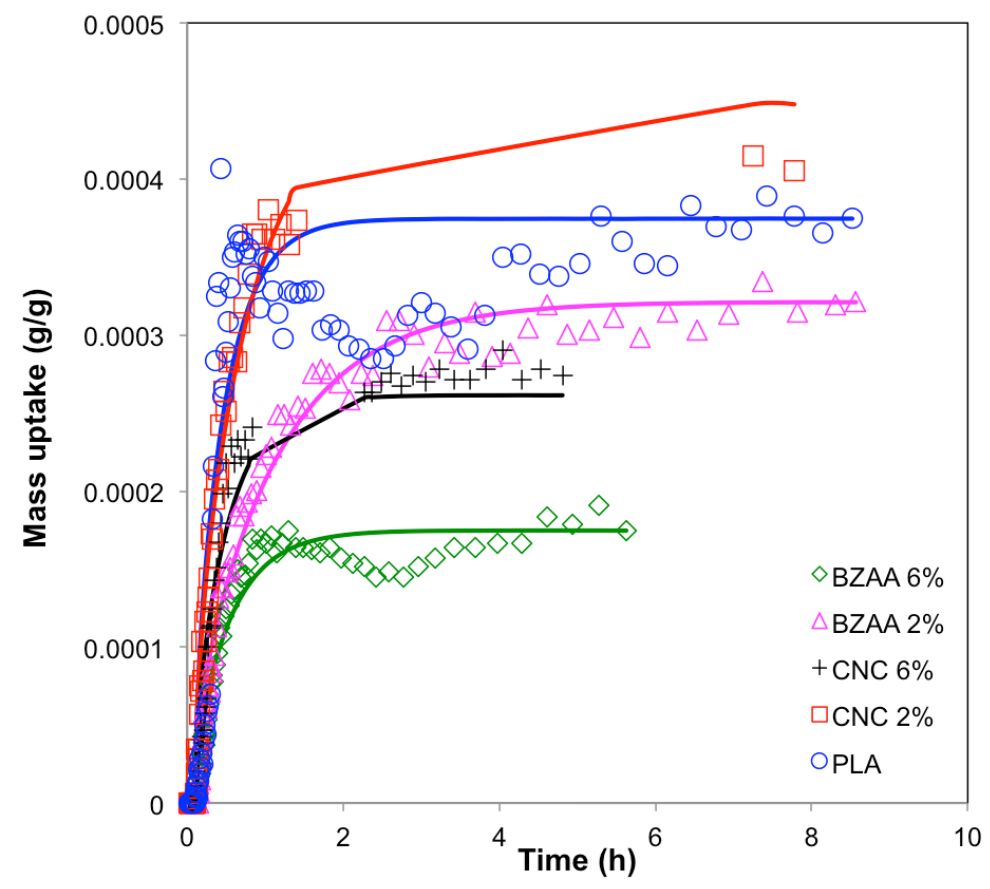

Figure 5. Cyclohexane mass uptake in PLA and PLA/CNC nanocomposites at 0.2 activity and $40^{\circ} \mathrm{C}$. The lines correspond to the fit for Fickian diffusion.

The sorption data of anisole in PLA and PLA/CNC nanocomposites are plotted in the Figure 6. One can observe the pressure perturbation which was introduced at regular time intervals in the aim to reregulate the partial pressure of anisole in the measurement chamber. The kinetics of the pressure perturbation were very different from the mass uptake kinetics, they were easily cancelled out. The 
anisole mass uptake was characterized by a Fickian and a non-Fickian transport regime (Fig. 6a). The non-Fickian mass transport regime was very present in the case of PLA/CNC (Fig. 6b) and PLA/CNC-gPhAA (Fig. 6d). It was much decreased in the case of PLA/CNC-g-BzAA (Fig. 6c), most likely due to a trapping effect of anisole at the CNC-g-BzAA interface. Indeed, as shown in (Espino-Perez et al., 2016), CNC-g-BzAA had the highest chemical affinity to anisole among the probed surface graftings.

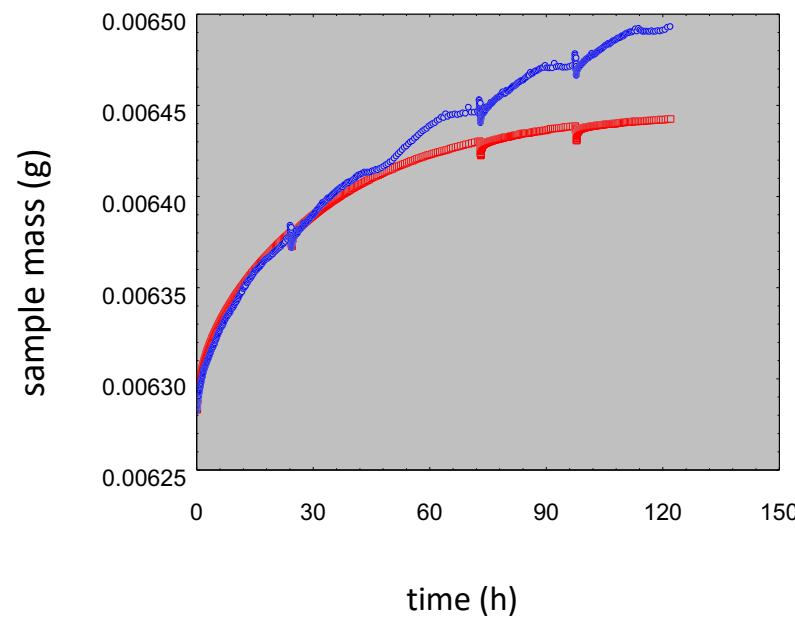

a. Anisole mass uptake in PLA

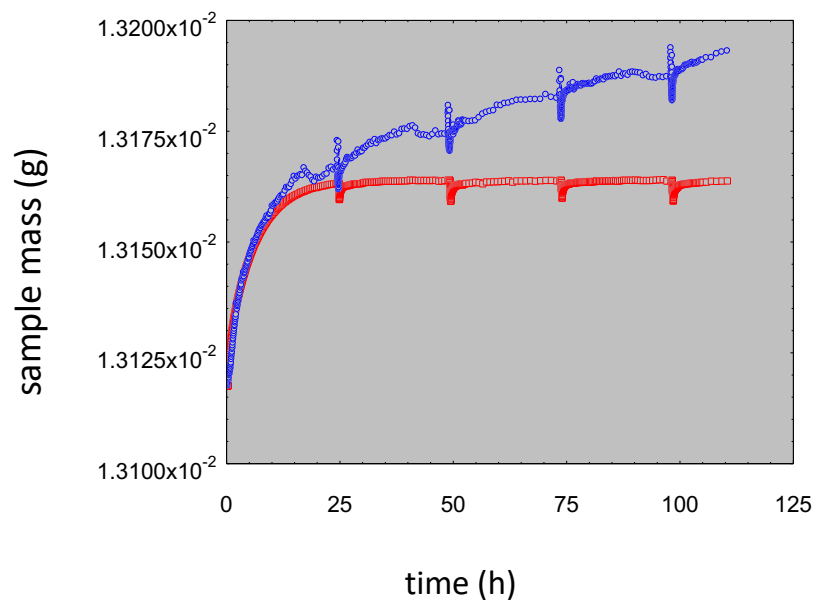

c. Anisole mass uptake in PLA/CNC-g-BZAA 6 wt\%

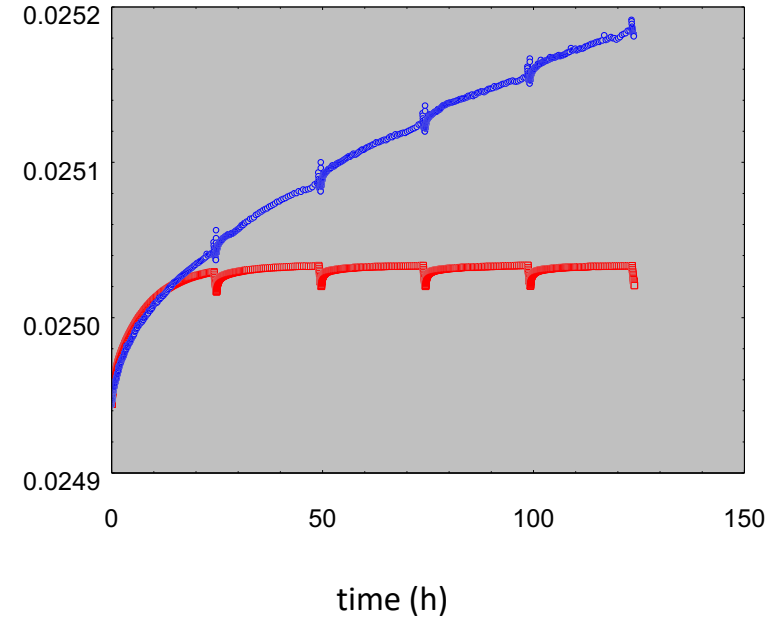

b. Anisole mass uptake in PLA/CNC 6 wt\%

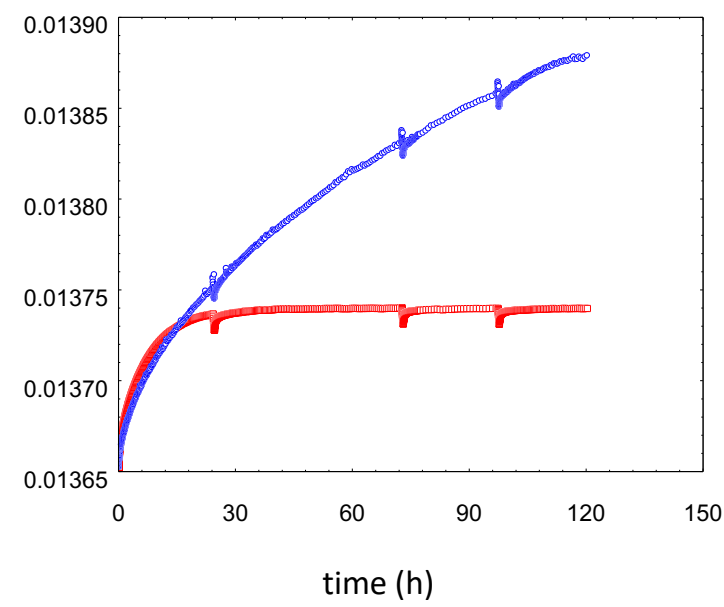

d. Anisole mass uptake in PLA/CNC-g-PhAA 6 wt\%

Figure 6. Raw data (blue lines) on modelling (red lines) of the sorption kinetics of anisole in PLA and $P L A / C N C$ nanocomposites nanocrystals at $40{ }^{\circ} \mathrm{C}$ and anisole activity $=0.2$.

\section{Acknowledgements}

This work was supported by the Mexican Scholarship Council (CONACyT) under grant No. 213840. We thank Alain Guinault (CNAM, UMR PIMM, Paris) for his help in the determination of the oxygen permeability properties of the film samples. 


\section{References}

Espino-Pérez, E., Bras, J., Almeida, G., Plessis, C., Belgacem, N., Perré, P., \& Domenek, S. (2018). Designed cellulose nanocrystal surface properties for improving barrier properties in polylactide nanocomposites. Carbohydrate Polymers, 183, 267-277.

Espino-Perez, E., Bras, J., Almeida, G., Relkin, P., Belgacem, N., Plessis, C., \& Domenek, S. (2016). Cellulose nanocrystal surface functionalization for the controlled sorption of water and organic vapours. Cellulose, 23(5), 2955-2970.

Espino-Perez, E., Domenek, S., Belgacem, N., Sillard, C., \& Bras, J. (2014). Green Process for Chemical Functionalization of Nanocellulose with Carboxylic Acids. Biomacromolecules, 15(12), 5441-4560.

Perre, P., Pierre, F., Casalinho, J., \& Ayouz, M. (2015). Determination of the Mass Diffusion Coefficient Based on the Relative Humidity Measured at the Back Face of the Sample During Unsteady Regimes. Drying Technology, 33(9), 1068-1075. 